\title{
Moist Static Energy Budget Analysis of Tropical Cyclone Intensification in High-Resolution Climate Models ${ }^{\mathscr{O}}$
}

\author{
Allison A. Wing, ${ }^{\mathrm{a}}$ Suzana J. Camargo, ${ }^{\mathrm{b}}$ Adam H. Sobel,${ }^{\mathrm{c}}$ Daehyun Kim, ${ }^{\mathrm{d}}$ Yumin Moon,${ }^{\mathrm{d}}$ \\ Hiroyuki Murakami, ${ }^{\mathrm{e}}$ KeVin A. Reed ${ }^{\mathrm{f}}$ Gabriel A. Vecchi, ${ }^{\mathrm{g}}$ Michael F. Wehner, ${ }^{\mathrm{h}}$ \\ COLIN ZARZYCKI, ${ }^{\mathrm{i}}$ AND MING ZHAO ${ }^{\mathrm{j}}$ \\ ${ }^{a}$ Department of Earth, Ocean and Atmospheric Science, Florida State University, Tallahassee, Florida \\ ${ }^{\mathrm{b}}$ Lamont-Doherty Earth Observatory, Columbia University, Palisades, New York \\ ${ }^{c}$ Department of Applied Physics and Applied Mathematics and Lamont-Doherty Earth Observatory, \\ Columbia University, New York, New York \\ ${ }^{\mathrm{d}}$ Department of Atmospheric Sciences, University of Washington, Seattle, Washington \\ ${ }^{\mathrm{e}}$ NOAA/Geophysical Fluid Dynamics Laboratory and Princeton University, Princeton, New Jersey \\ ${ }^{\mathrm{f}}$ School of Marine and Atmospheric Sciences, Stony Brook University, Stony Brook, New York \\ ${ }^{\mathrm{g}}$ Department of Geosciences and Princeton Environmental Institute, Princeton University, Princeton, New Jersey \\ ${ }^{\mathrm{h}}$ Lawrence Berkeley National Laboratory, Berkeley, California \\ ${ }^{\mathrm{i}}$ National Center for Atmospheric Research, Boulder, Colorado \\ ${ }^{\mathrm{j}}$ NOAA/Geophysical Fluid Dynamics Laboratory, Princeton, New Jersey
}

(Manuscript received 11 September 2018, in final form 28 May 2019)

\begin{abstract}
Tropical cyclone intensification processes are explored in six high-resolution climate models. The analysis framework employs process-oriented diagnostics that focus on how convection, moisture, clouds, and related processes are coupled. These diagnostics include budgets of column moist static energy and the spatial variance of column moist static energy, where the column integral is performed between fixed pressure levels. The latter allows for the quantification of the different feedback processes responsible for the amplification of moist static energy anomalies associated with the organization of convection and cyclone spinup, including surface flux feedbacks and cloud-radiative feedbacks. Tropical cyclones (TCs) are tracked in the climate model simulations and the analysis is applied along the individual tracks and composited over many TCs. Two methods of compositing are employed: a composite over all TC snapshots in a given intensity range, and a composite over all TC snapshots at the same stage in the TC life cycle (same time relative to the time of lifetime maximum intensity for each storm). The radiative feedback contributes to TC development in all models, especially in storms of weaker intensity or earlier stages of development. Notably, the surface flux feedback is stronger in models that simulate more intense TCs. This indicates that the representation of the interaction between spatially varying surface fluxes and the developing TC is responsible for at least part of the intermodel spread in TC simulation.
\end{abstract}

\section{Introduction}

The study of tropical cyclones (TCs) in climate models has long been difficult because of the conflict between the high resolution necessary to accurately simulate TCs and the need to perform long, global simulations. In recent years, however, enormous progress has been made

Supplemental information related to this paper is available at the Journals Online website: https://doi.org/10.1175/JCLI-D-180599.s1.

Corresponding author: Allison A. Wing, awing@fsu.edu in the ability of general circulation models (GCMs) to simulate TCs from subseasonal to seasonal and longer time scales (Camargo and Wing 2016). Global forecast models have become a more reliable source of tropical cyclone genesis guidance (e.g., Halperin et al. 2016) while climate models have improved such that they can reproduce the TC climatology with some fidelity (e.g.,

Publisher's Note: This article was revised on 29 June 2021 to correct the citations to two equations in the first two sentences of section $b$ in the Appendix, which were mislabeled when originally published. 
TABLE 1. Description of model simulations.

\begin{tabular}{|c|c|c|c|c|c|}
\hline Model & Resolution & Dynamical core & Convection scheme & Tracking algorithm & Other notes \\
\hline HiRAM & $\sim 50 \mathrm{~km}$ & $\begin{array}{l}\text { Finite volume } \\
\text { cubed sphere }\end{array}$ & $\begin{array}{l}\text { Bretherton et al. } \\
\text { (2004) }\end{array}$ & Zhao et al. (2009) & $\begin{array}{l}\text { Other physics from } \\
\text { GFDL AM2 }\end{array}$ \\
\hline AM2.5 & $\sim 50 \mathrm{~km}$ & $\begin{array}{l}\text { Finite volume } \\
\text { cubed sphere }\end{array}$ & $\begin{array}{l}\text { Relaxed Arakawa- } \\
\text { Schubert }\end{array}$ & $\begin{array}{c}\text { Murakami et al. (2015), } \\
\text { Harris et al. (2016) }\end{array}$ & $\begin{array}{l}\text { Other physics from } \\
\text { GFDL AM2 }\end{array}$ \\
\hline FLOR & $\sim 50 \mathrm{~km}$ & $\begin{array}{l}\text { Finite volume } \\
\text { cubed sphere }\end{array}$ & $\begin{array}{l}\text { Relaxed Arakawa- } \\
\text { Schubert }\end{array}$ & $\begin{array}{l}\text { Murakami et al. (2015), } \\
\text { Harris et al. (2016) }\end{array}$ & $\begin{array}{l}\text { Coupled to } 1^{\circ} \text { ocean, } \\
\text { SST nudged to obs }\end{array}$ \\
\hline CAM-FV & $\sim 25 \mathrm{~km}$ & $\begin{array}{l}\text { Finite volume } \\
\text { latitude-longitude }\end{array}$ & $\begin{array}{l}\text { Park and Bretherton } \\
\text { (2009), Zhang and } \\
\text { McFarlane (1995) }\end{array}$ & Zhao et al. (2009) & NCAR-DOE CAM5 \\
\hline CAM-SE & $\begin{array}{l}\sim 25 \mathrm{~km} \text { in North } \\
\text { Atlantic, } \sim 100 \mathrm{~km} \\
\text { global }\end{array}$ & Spectral element & $\begin{array}{l}\text { Park and Bretherton } \\
\text { (2009), Zhang and } \\
\text { McFarlane (1995) }\end{array}$ & $\begin{array}{l}\text { Ullrich and Zarzycki } \\
\text { (2017), Zarzycki } \\
\text { et al. (2017) }\end{array}$ & NCAR-DOE CAM5 \\
\hline GEOS & $\sim 50 \mathrm{~km}$ & $\begin{array}{l}\text { Finite volume } \\
\text { cubed sphere }\end{array}$ & $\begin{array}{l}\text { Relaxed Arakawa- } \\
\text { Schubert }\end{array}$ & Camargo and Zebiak & MERRA-2 AMIP \\
\hline
\end{tabular}

Zhao et al. 2009; Wehner et al. 2014) and exhibit some skill in seasonal forecasting (Zhang et al. 2016; Vecchi et al. 2014; Murakami et al. 2015, 2016; Vitart et al. 2010; Chen and Lin 2011, 2013). This is largely a result of algorithmic and computational advances that have allowed for the use of high horizontal resolutions that substantially improve the simulation of TC climatology, structure, and intensity. However, biases remain. For example, low-resolution GCMs tend to simulate too few TCs globally (Camargo 2013), and even 50-km highresolution models are generally not able to simulate the most intense storms (Shaevitz et al. 2014). While decreasing the model grid spacing can improve the low intensity bias (Manganello et al. 2012; Wehner et al. 2014; Murakami et al. 2015), it does not do so uniformly (Roberts et al. 2015), and even in models with the same resolution there can be substantial differences in their ability to simulate TCs (Shaevitz et al. 2014). This suggests that resolution is not the only factor controlling model simulation of TCs. In particular, TCs are tightly coupled to clouds and convection, so TC frequency, intensity, structure, and interannual variability are strongly sensitive to the details of convective parameterizations (e.g., Reed and Jablonowski 2011; Murakami et al. 2012; Zhao et al. 2012; Kim et al. 2012; Duvel et al. 2017). These biases contribute to uncertainty regarding future projections of TC activity (Walsh et al. 2016), as such projections depend on the ability of GCMs to reliably capture the features of TC activity.

Our objective is to develop process-oriented diagnostics to identify model characteristics that are responsible for proper simulation of TCs and that will explain the intermodel spread in TC frequency and intensity distributions. These diagnostics go beyond simply quantifying the simulated TC activity and focus on how simulated TCs respond to their environments, rather than how the largescale environment itself is simulated across different models. Our study builds on the work of Kim et al. (2018), which introduced a suite of diagnostics that provided deeper insights into the representation of physical processes that are responsible for the simulation of TCs in GCMs. The Kim et al. (2018) diagnostics consist of azimuthal averages of dynamic and thermodynamic fields around the storm center and identify physical processes related to the interaction between convection, moisture, and circulation that can lead to intermodel differences in simulated TCs. Of the three models examined, they found that the one with the most intense storms had the most precipitation near the composite TC center, the strongest sensitivity of convection to moisture, and the strongest contrast in relative humidity and surface latent heat flux between the inner and outer region of the composite TCs. These results indicate the importance of moistureconvection coupling and feedbacks between the surface latent heat flux and convection. Here, we develop and apply an additional, related set of diagnostics to further analyze the role of these and other processes in simulated TCs, in six high-resolution climate models.

The paper is organized as follows. We provide a brief description of the six high-resolution models used in this study in section 2 and describe our diagnostics and analysis methodology in section 3. The application of these diagnostics to the six models will be described in section 4 , with a discussion of their implications in section 5. We provide a summary of the results and conclusions in section 6 .

\section{Model simulations}

\section{a. Models}

We explore TC intensification processes in six highresolution climate model long-term ( $>20$ year) historical simulations (Table 1). Several of these simulations were also examined in complementary studies by Kim et al. (2018) and Y. Moon et al. (2019, manuscript submitted to J. Climate). This six-member model ensemble is 
an "ensemble of opportunity" based on available simulations, rather than a coordinated intercomparison.

Three of the models were developed at the Geophysical Fluid Dynamics Laboratory (GFDL) Atmosphere Model version 2.5 (AM2.5; Delworth et al. 2012), High Resolution Atmospheric Model (HiRAM; Zhao et al. 2009), and Forecast-Oriented Low Ocean Resolution (FLOR; Vecchi et al. 2014) version of Coupled Model 2.5 (CM2.5; Delworth et al. 2012). AM2.5 and HiRAM are atmosphere-only simulations forced with observed sea surface temperatures from HadISST1.1 (Rayner et al. 2003), while FLOR is a coupled simulation in which SSTs are calculated interactively by its oceanic component and nudged toward the observed SSTs with a 5-day nudging time scale. This ensures the model mean state remains close to that observed. The ocean component of FLOR has $1^{\circ} \times 1^{\circ}$ horizontal resolution, zooming to $1 / 3^{\circ}$ meridional spacing near the equator with 50 vertical levels, and an ocean-atmosphere coupling interval of $1 \mathrm{~h}$. The atmosphere component of FLOR is AM2.5. All three GFDL models are run with $50-\mathrm{km}$ horizontal resolution and 32 vertical levels in the atmosphere and use the same finite volume dynamical core on a cubed-sphere grid (Putman and Lin 2007), with the same divergence damping coefficient (Zhao et al. 2012), the same time steps, and the same physicsdynamics coupling interval (the gravity wave, advective, and physics time steps are 200,600 , and 1200 s, respectively, and the radiation is called every $3 \mathrm{~h}$ ). AM2.5 and FLOR use the same relaxed Arakawa-Schubert convection scheme (Moorthi and Suarez 1992), while HiRAM uses a version of the Bretherton et al. (2004) shallow convection scheme, modified to simulate both deep and shallow convection (Zhao et al. 2012); all other physics packages are the same (Anderson et al. 2004). Therefore, AM2.5 and FLOR differ only in that FLOR is coupled while AM2.5 is atmosphere-only, and AM2.5 and HiRAM differ only in their convection schemes.

Two of the additional atmosphere-only models we analyze are versions of the National Center for Atmospheric Research (NCAR)-Department of Energy (DOE) Community Atmosphere Model, version 5 (CAM5; Neale et al. 2012) with both the spectral element (CAM-SE; Dennis et al. 2012) and the finite volume (CAM-FV; Lin and Rood 1996, 1997) dynamical cores. CAM-SE is configured with the variable-resolution option (Zarzycki et al. 2014), with $0.25^{\circ}$ grid spacing over the North Atlantic and $1^{\circ}$ grid spacing elsewhere as in Zarzycki et al. (2017). The raw data are remapped to a globally uniform $0.25^{\circ}$ latitude-longitude grid, although we restrict our analysis to the North Atlantic where the native resolution is highest. CAM-FV is configured with global $0.25^{\circ}$ grid, similar to the work of Wehner et al. (2014). CAM5 utilizes 30 vertical levels with a model top of approximately $2 \mathrm{hPa}$. The prescribed SST and sea ice boundary dataset for both simulations is provided from Hurrell et al. (2008). Both CAM-SE and CAM-FV use similar versions of the CAM5 physics parameterizations, including the same deep (Zhang and McFarlane 1995) and shallow convective (Park and Bretherton 2009) schemes, moist boundary layer turbulence scheme (Bretherton and Park 2009), and Rapid Radiative Transfer Model for GCMs (RRTMG; Mlawer et al. 1997) scheme. Therefore, CAMSE and CAM-FV differ primarily in their dynamical cores, which has previously been shown to impact the simulation of TC climatology in the model (Reed et al. 2015).

The sixth atmosphere-only model simulation we analyze is one member of the M2-AMIP [for Modern-Era Retrospective Analysis for Research and Applications, version 2 (MERRA-2; Gelaro et al. 2017) Atmospheric Model Intercomparison Project (AMIP)] set of simulations (Collow et al. 2017, 2018) performed with the NASA Goddard Earth Observing System Model version 5, version 5.12.4 (GEOS; Rienecker et al. 2008; Molod et al. 2015). This version of the atmosphere component of GEOS is the same model that was used for MERRA-2, the most recent NASA reanalysis data product, but the simulation we analyze is a free-running version of the model initialized in November 1979 and driven by the MERRA-2 SST and sea ice boundary conditions (Bosilovich et al. 2015). GEOS employs a finitevolume dynamical core (Putman and Lin 2007) with a c180 cubed-sphere grid (an approximate horizontal resolution of $50 \mathrm{~km}$ ), which is then spatially interpolated to a $0.625^{\circ} \times 0.5^{\circ}$ longitude-latitude grid. The native model vertical grid has 72 terrain-following hybrid-eta levels. GEOS employs a relaxed Arakawa-Schubert convection scheme (Moorthi and Suarez 1992) and parameterizations for longwave (Chou and Suarez 1994) and shortwave (Chou and Suarez 1999) radiation; other details on the physics packages can be found in Molod et al. (2015).

\section{b. TC detection and tracking}

TC-like vortices (which we refer to simply as "TCs") are detected and tracked from the model fields using standard tracking algorithms from each modeling group, which produce, for each TC, a time series of the TC's center longitude and latitude, minimum sea level pressure, and maximum wind speed corrected to a surface $(10 \mathrm{~m})$ value. We refer to the maximum surface wind speed as the TC "intensity." Each tracked TC has an intensity at each snapshot along its track as well as a lifetime maximum intensity (LMI), which is the maximum intensity found at any time along its track.

The TCs in the HiRAM simulation are tracked using the routine described in Zhao et al. (2009), which is based 
on Vitart et al. (1997, 2003) and Knutson et al. (2007). This algorithm locates grid points with an 850-hPa relative vorticity maximum, local sea level pressure minimum, and warm core, and tracks the storm by searching for a vortex in the next snapshot within a distance of $400 \mathrm{~km}$ and connecting the snapshots. It requires that storms last at least 3 days and have an intensity greater than $17 \mathrm{~m} \mathrm{~s}^{-1}$ during at least 3 (not necessarily consecutive) days.

The tracking scheme used in AM2.5 and FLOR is similar to that used in HiRAM and is described in Murakami et al. (2015) and Harris et al. (2016). This algorithm uses local sea level pressure minimum and a warm core criteria to detect TCs and requires that storms last at least 3 days, be warm core for at least 2 days, and have an intensity greater than $15.75 \mathrm{~m} \mathrm{~s}^{-1}$ during at least $36 \mathrm{~h}$ while the storm has a warm core.

The TCs in the CAM-SE simulation are tracked using TempestExtremes (Ullrich and Zarzycki 2017; Zarzycki et al. 2017), while the TCs in the CAM-FV simulation are tracked using the dectection algorithm from Zhao et al. (2009). TempestExtremes (Ullrich and Zarzycki 2017; Zarzycki et al. 2017) searches for a local minimum in sea level pressure and a collocated local maximum in geopotential thickness between the 300- and 500-hPa levels (which indicates a warm core). Candidate cyclones are then stitched together in time, with storms needing to be equatorward of $40^{\circ}$ latitude for at least $60 \mathrm{~h}$ (not necessarily consecutive), and separate trajectories that terminate and begin within $12 \mathrm{~h}$ and $10^{\circ}$ of one another are merged to eliminate double-counting of broken tracks.

The TCs in the GEOS simulation are tracked using the Camargo and Zebiak (2002) tracking algorithm, which has been widely applied to various global and regional climate models (e.g., Camargo 2013). This algorithm uses basin-dependent thresholds of low-level vorticity, surface wind speed, and vertically integrated temperature anomaly to detect TCs, then tracks the lowlevel vorticity center forward and backward in time from each point that has met the detection criteria. For this study, we additionally require that the vortex have an intensity greater than $15.2 \mathrm{~m} \mathrm{~s}^{-1}$ for 3 days (not necessarily consecutive). If this threshold is not applied, the Camargo and Zebiak (2002) algorithm detects many more weak storms, which shifts the intensity distribution in GEOS toward weaker wind speeds and increases the sample size of total storms, but does not otherwise have a significant impact on our results or conclusions (shown in the online supplemental material).

\section{Analysis methodology}

While long-term simulations were performed, for most models we only have high-frequency (6 hourly),
TABLE 2. Years and number of tropical cyclones (TCs) for which moist static energy budget analysis is performed. Only TCs in the North Atlantic are analyzed in CAM-SE.

\begin{tabular}{lcc}
\hline \multicolumn{1}{c}{ Model } & Years analyzed & No. of TCs \\
\hline HiRAM & $1984-85$ & 203 \\
AM2.5 & $1984-85$ & 170 \\
FLOR & $1984-85$ & 211 \\
CAM-FV & $1996-97$ & 146 \\
CAM-SE & $1992-99$ & 91 \\
GEOS & $1984-85$ & 84 \\
\hline
\end{tabular}

model level output available for two years, so we apply our moist static energy budget analysis along individual simulated tropical cyclone tracks during those two years. Eight years, 1992-99, are analyzed for the CAM-SE simulation, so that the number of TCs analyzed is comparable to the other models, since we only analyze TCs in the North Atlantic in CAM-SE, compared with the global distribution of TCs in the other models. The TC statistics in the several years analyzed are representative of the model climatology, in each model. We perform our analysis in $10^{\circ}$ boxes centered on each TC and following each TC. When making composites, we exclude points over land and TCs that have moved poleward of $30^{\circ}$. The years examined and the number of TCs analyzed from those years are shown in Table 2.

We compute budgets of column-integrated moist static energy and the spatial variance of column-integrated moist static energy. Moist static energy is approximately conserved under moist adiabatic processes, and its column integral is unchanged by convection (Emanuel 1994). The analysis framework for the variance budget was first developed by Wing and Emanuel (2014) to understand the physical mechanisms of self-aggregation of convection in idealized simulations. It has since been applied to simulations of tropical convection in a variety of idealized and realistic configurations (Arnold and Randall 2015; Wing and Cronin 2016; Coppin and Bony 2015; Holloway and Woolnough 2016; Becker et al. 2017; Holloway 2017) and to cloud-resolving model simulations of tropical cyclones (Wing et al. 2016; Muller and Romps 2018). Column-integrated moist static energy $\hat{h}$ is given by

$$
\hat{h}=\frac{1}{g} \int_{p_{t}}^{p_{b}}\left(c_{p} T+g z+L_{v} q\right) d p
$$

where $p_{t}$ is the pressure at the model top, $p_{b}$ is the pressure at the bottom, $q$ is the water vapor mixing ratio, and all other variables have their usual meaning. We perform our analysis on model levels where $p_{b}$ is set to $920 \mathrm{hPa}$ and $p_{t}$ is set to the model top. We describe the motivations for and implications of this choice in the 
appendix. The budget for column-integrated moist static energy is given by

$$
\frac{\partial \hat{h}}{\partial t}=F_{k}+N_{L}+N_{S}-\overline{\mathbf{u} \cdot \nabla h},
$$

where $F_{k}$ is the surface moist enthalpy flux, $N_{L}$ is the column longwave radiative flux convergence, and $N_{S}$ is the column shortwave radiative flux convergence. Each of these terms [as well as advection, the last term on the right-hand side of Eq. (2)] is a source or sink of $\hat{h}$. The terms $F_{k}, N_{L}$, and $N_{S}$ are output as temporal averages (6-hourly for HiRAM, AM2.5, and FLOR, 3-hourly for CAM-SE and CAM-FV, and 1-hourly for GEOS); we average consecutive periods together to derive a value centered around the time of the TC snapshot. The term $\hat{h}$ is computed as described above and in the appendix, using instantaneous output at the time of the TC snapshot, and $\partial \hat{h} / \partial t$ is computed using a centered finite difference. Given the uncertainties associated with calculating the advection of moist static energy from offline model output, we calculate the advective term as a residual from the rest of the budget. As Eq. (2) neglects the tendency of kinetic energy and is therefore only an approximation, this residual may include more than just the advective term, as is discussed in more detail in the appendix. All terms are computed at each grid point within the $10^{\circ}$ box centered on the TC (Villarini et al. 2014; Scoccimarro et al. 2014).

For each grid point, the contributions to the tendency of the spatial variance of $\hat{h}$ is given by

$\frac{1}{2} \frac{\partial \hat{h}^{2}}{\partial t}=\hat{h}^{\prime} \frac{\hat{h}^{\prime}}{\partial t}=\hat{h}^{\prime} F_{k}^{\prime}+\hat{h}^{\prime} N_{L}^{\prime}+\hat{h}^{\prime} N_{S}^{\prime}-\hat{h}^{\prime}(\overline{\mathbf{u} \cdot \nabla h})^{\prime}$,

where primes indicate anomalies from the mean of the $10^{\circ} \times 10^{\circ}$ box centered around a TC. As convection organizes and the TC forms, the convecting areas become moister and the surrounding nonconvecting areas become drier. This is manifest as an increase in the spatial variance of $\hat{h}$ computed over a box surrounding the developing storm. ${ }^{1}$ Each of the terms on the righthand side of Eq. (3) measures the contribution of a feedback to the increase in $\hat{h}$ variance; a positive feedback indicates that the processes amplifies $\hat{h}$ anomalies, such as enhanced surface fluxes in an area of already moister than average air. In idealized simulations, the moist static energy variance always increases as the TC forms and intensifies (Wing et al. 2016), but this does not

\footnotetext{
${ }^{1}$ While both temperature and moisture variability contribute to the spatial variance of $\hat{h}$, the moisture contribution is dominant (not shown).
}

necessarily have to generalize to more realistic simulations (or nature). We find that the moist static energy variance increases with $\mathrm{TC}$ intensification in the climate model simulations (see sections $4 \mathrm{~d}$ and $4 \mathrm{e}$, and the appendix), which provides empirical justification for our analysis methodology.

We calculate each term in the two budgets at each grid point in the box following the tracks of each simulated TC. We then composite over the simulated TCs in two different ways:

1) a life cycle composite, where all snapshots at the same time relative to the time of lifetime maximum intensity (LMI) of each TC are averaged together; and

2) an intensity-bin composite, where all snapshots in which the TC has intensity in a given range are averaged together.

In the life cycle composite, we examine times prior to the LMI in 6-h increments, and go backward in time until the composite contains less than $25 \%$ of the total number of TCs (so that the composite is a representative sample; note that the lifetime varies from storm to storm). This allows us to assess how different processes are contributing to the formation and intensification of the composite TC in each model as it moves through its life cycle, and can be compared to similar analysis for idealized TCs simulated with explicit convection (Wing et al. 2016). When comparing the different models, however, the composite intensity may be quite different at the same life cycle stage, which may contribute to a feedback being stronger or weaker. This motivates the use of the intensity-bin composite, following Kim et al. (2018), in which the model-to-model comparison is made using TC snapshots at the same intensity. Only TC snapshots up until the time of the LMI of a given storm are included in the composite. The intensity bins used for this composite analysis and the number of snapshots in each bin are given in Table 3.

\section{Results}

\section{a. General characteristics of TC simulation}

As an overview of the TC climatology in the six simulations we examine, the genesis positions for the tracked TCs in each model, and in the best-track observational data, ${ }^{2}$ is shown in Fig. 1 . Five years of TC

\footnotetext{
${ }^{2}$ Tracks in the North Atlantic and eastern North Pacific are from the National Hurricane Center (Landsea and Franklin 2013), and tracks in other basins are from the Joint Typhoon Warning Center (Chu et al. 2002).
} 
TABLE 3. TC intensity bins and number of snapshots per bin.

\begin{tabular}{|c|c|c|c|c|c|c|c|}
\hline Bin & Intensity range $\left(\mathrm{m} \mathrm{s}^{-1}\right)$ & HiRAM & AM2.5 & FLOR & CAM-FV & CAM-SE & GEOS \\
\hline 1 & $6 \leq V_{m}<9$ & 0 & 4 & 5 & 0 & 3 & 254 \\
\hline 2 & $9 \leq V_{m}<12$ & 0 & 142 & 154 & 1 & 15 & 504 \\
\hline 3 & $12 \leq V_{m}<15$ & 41 & 413 & 512 & 25 & 72 & 721 \\
\hline 4 & $15 \leq V_{m}<18$ & 431 & 628 & 736 & 246 & 131 & 944 \\
\hline 5 & $18 \leq V_{m}<21$ & 630 & 667 & 994 & 673 & 173 & 524 \\
\hline 6 & $21 \leq V_{m}<24$ & 540 & 645 & 884 & 935 & 184 & 247 \\
\hline 7 & $24 \leq V_{m}<27$ & 440 & 435 & 543 & 808 & 154 & 110 \\
\hline 8 & $27 \leq V_{m}<30$ & 306 & 266 & 256 & 604 & 119 & 74 \\
\hline 9 & $30 \leq V_{m}<33$ & 236 & 145 & 126 & 488 & 88 & 23 \\
\hline 10 & $33 \leq V_{m}<35$ & 92 & 49 & 47 & 232 & 59 & 9 \\
\hline 11 & $35 \leq V_{m}<38$ & 125 & 20 & 24 & 272 & 60 & 12 \\
\hline 12 & $38 \leq V_{m}<41$ & 102 & 8 & 3 & 239 & 45 & 3 \\
\hline 13 & $41 \leq V_{m}<44$ & 84 & 3 & 4 & 167 & 49 & 0 \\
\hline 14 & $44 \leq V_{m}<47$ & 43 & 4 & 0 & 102 & 31 & 0 \\
\hline 15 & $47 \leq V_{m}<50$ & 9 & 0 & 0 & 101 & 32 & 0 \\
\hline
\end{tabular}

genesis positions, from 1995 to 2000, are shown for each model and for observations. These are not the same years that are analyzed in detail in subsequent sections of this paper and are only meant to give an indication of what the TC distribution in these models looks like. While all models have reasonable spatial distributions and genesis frequency of TCs, there are large differences between them and clear biases compared to the observations. Many of the models struggle to accurately simulate the genesis distribution in the North Atlantic, for example. Overall, HiRAM and FLOR form the most TCs, which is also true in the two years of data we analyze in detail (Table 2). Note that it is expected that CAM-SE generates few TCs outside of the Atlantic because the high-resolution region is confined to only that basin.

The distribution of lifetime maximum intensity for the simulated TCs in each model is shown in Fig. 2a, for only the two years that we analyze in detail (see Table 2), and, for CAM-SE, only for TCs in the North Atlantic. The observed LMI distribution from 1995 to 2000 is also plotted in Fig. 2a, for reference. The distribution of intensity at each snapshot along the TC track up until the time of LMI is shown in Fig. 2b; these are the data used for the intensity-bin composite. CAM-SE and CAM-FV simulate significantly stronger storms than the other four models, as expected due to their finer grid spacing. CAM-SE has a greater likelihood of simulating storms at the high-intensity tail of the distribution than CAM-FV, consistent with Reed et al. (2015), although the mean LMI over all storms is higher in CAM-FV. However, resolution is not the only source of intermodel spread in intensity. The TCs in HiRAM are noticeably stronger than those in AM2.5, FLOR, and GEOS, despite those models having similar resolution. All the models have a low-intensity bias compared to the best-track observations (dashed line in Fig. 2a). Only a few of the models show evidence of the observed bimodal distribution of intensity, where the secondary peak in LMI is associated with storms that undergo rapid intensification (Lee et al. 2016).

The multiple tracking algorithms used across the simulations could contribute to these differences. Cursory analysis found minimal differences in TC statistics in the CAM-SE and CAM-FV simulations, limited to weaker storms, when applying both the Zhao et al. (2009) and TempestExtremes algorithms to the same dataset (not shown). We performed more in-depth analysis (repeating all calculations described in subsequent sections, shown in the online supplemental material) for the case in which the GFDL tracking algorithm (used for AM2.5 and FLOR; Murakami et al. 2015; Harris et al. 2016) was also applied to HiRAM (cyan curve in Fig. 2, referred to as HiRAM-G). When applied to the HiRAM simulation, the GFDL algorithm yields weaker TCs than the HiRAM (Zhao et al. 2009) algorithm does (blue curve in Fig. 2). We speculate that this is because the Murakami et al. (2015) implementation of the Harris et al. (2016) algorithm has less strict wind speed conditions for detecting TCs than does the HiRAM algorithm, allowing the GFDL algorithm to detect more weaker TCs, and to track those TCs for longer, which impacts the likelihood of observing any individual intensity (note that for an individual TC snapshot at the same time and location, the two algorithms yield the same intensity). Importantly, we find that the sensitivity to tracking algorithm does not cause any significant differences in the results of our moist static energy variance budget analysis. Some of the terms in the moist static energy variance budget have slightly smaller values in HiRAM-G than in HiRAM (shown in the supplemental material), but this does not 
(a) CAM-SE

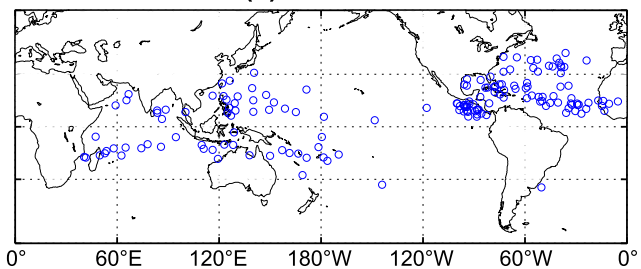

(c) HiRAM

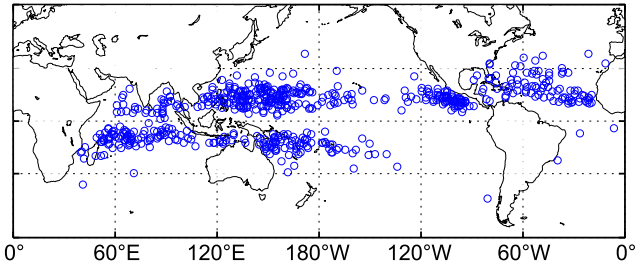

(e) FLOR

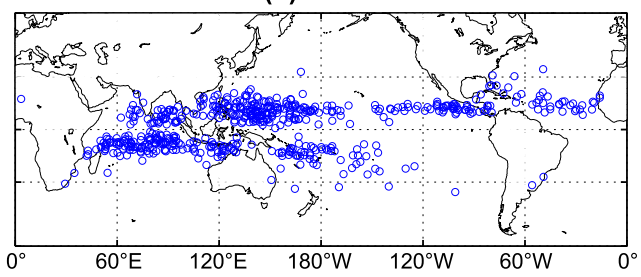

(b) CAM-FV

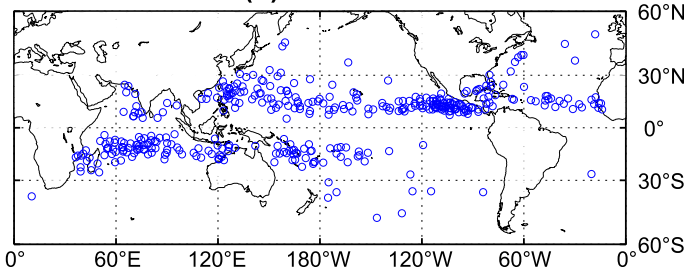

(d) AM2.5

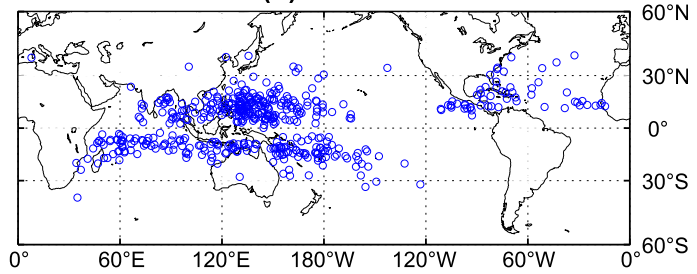

(f) GEOS

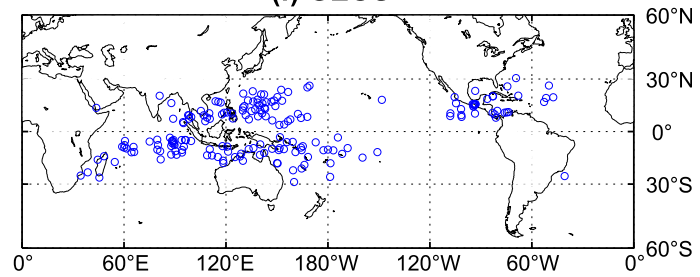

(g) Observations

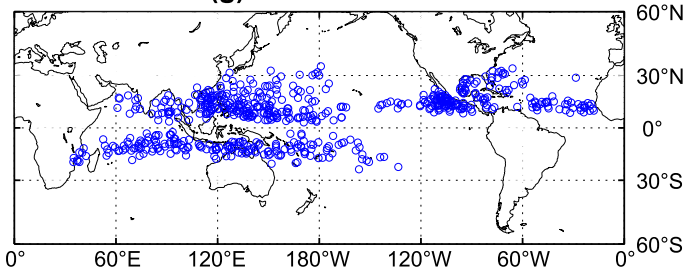

FIG. 1. Genesis positions for tropical cyclones (a)-(f) in each model and (g) in the best-track observational data, for 1995-2000. Data from these five years are plotted because they are the years for which the long-term model simulations overlap with each other. For the models, the genesis position is the latitude and longitude of the first point in the track, as determined by the tracking algorithm.

change the comparison to the other models or any of our conclusions.

\section{b. Moist static energy budget}

We first examine the evolution of the moist static energy budget over the composite TC life cycle [Eq. (2)]. Each term in the moist static energy budget composited $48 \mathrm{~h}$ prior to the LMI of the simulated TCs is shown, for the CAM-FV simulation, in Fig. 3. The signature of the TC can be easily seen in the spatial distribution of column moist static energy, which is larger near the TC center due to the warm, moist air there (Fig. 3b). The moist static energy of the composite TC generally increases as it intensifies toward its LMI, as can been seen in an animation of the evolution of the moist static energy budget with time over the composite TC life cycle (found in the supplemental material), and in the positive tendency of $\hat{h}$ in the vicinity of the TC (Fig. 3c). The column radiative flux convergence is generally negative (cooling) and thus a sink of moist static energy. At this particular time, however, it is actually slightly positive (indicating net column radiative heating) in the vicinity of the TC (Fig. 3d), which reflects the influence of the moist air and thick cloud shield associated with the TC. The surface enthalpy fluxes are positive, and are therefore a source of moist static energy (Fig. 3e). They are larger in the vicinity of the TC because of the larger surface winds there. The advection of moist static energy is generally negative and downgradient, although since this term is calculated as a residual we cannot be certain that it is entirely and only representing advection (Fig. 3f). These relationships are also found in the other 
(a) Lifetime Maximum Intensity (LMI)

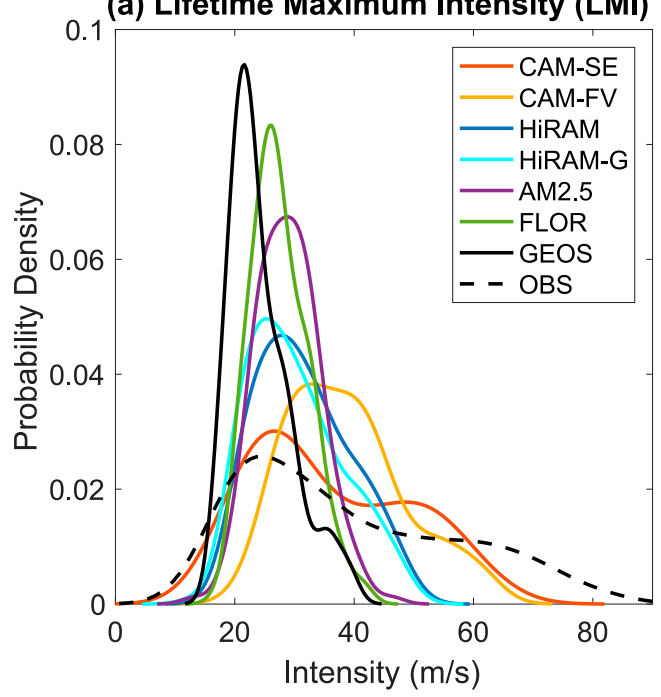

(b) Intensity

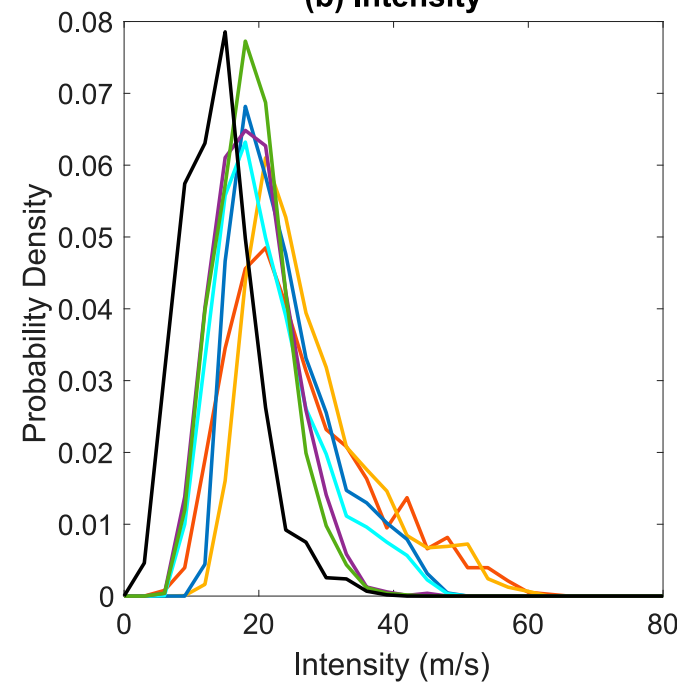

FIG. 2. Probability density function of (a) LMI and (b) the intensity at each snapshot along the TC track up until the time of LMI, for the two years of TCs that are analyzed in each model (see Table 2), excluding snapshots poleward of $30^{\circ}$ and, in CAM-SE, excluding storms outside of the North Atlantic. "HiRAM-G" (in cyan) indicates TCs in the HiRAM simulation that have been identified and tracked using the GFDL tracking algorithm (the same as used for AM2.5 and FLOR; Murakami et al. 2015). The black dashed line in (a) shows, for reference, the observed distribution of LMI from the best-track data, for storms of at least tropical storm strength (LMI $\geq$ $17 \mathrm{~m} \mathrm{~s}^{-1}$ ) from 1995 to 2000 , and equatorward of $30^{\circ}$. The PDF in (a) is smoothed while the PDF in (b) uses the unsmoothed $3 \mathrm{~m} \mathrm{~s}^{-1}$ bins from Table 3 (extended to $93 \mathrm{~m} \mathrm{~s}^{-1}$ ).

models; equivalent figures and animations for the other five models are provided in the supplemental material.

\section{c. Moist static energy variance budget}

As noted above, the moist static energy of the TC increases as the TC forms and intensifies; in particular, it increases relative to the moist static energy of the surrounding environment. This should be reflected in an increase in the spatial variance of the moist static energy. To quantify the feedbacks that may contribute to a change in the spatial variability of $\hat{h}$, we now examine the $\hat{h}$ variance budget over the composite TC life cycle [Eq. (3)]. Each term in the $\hat{h}$ variance budget composited $48 \mathrm{~h}$ prior to the LMI of the simulated TCs is shown, for the CAM-FV simulation, in Fig. 4. As could be inferred from Fig. $3, \hat{h}$ is anomalously high in the vicinity of the TC. The tendency of $\hat{h}^{\prime 2}$ is noisy but positive near the TC center (Fig. 4c). Both the radiative and surface flux feedbacks are positive, indicating that both of these processes contribute to the amplification of $\hat{h}$ anomalies. The radiative feedback is positive throughout the domain, but largest near the center of the TC where the anomalously high $\hat{h}$ is coincident with reduced column radiative cooling associated with thick cloud cover (Fig. 4d). The surface flux feedback is most positive near the TC eyewall, where the largest surface winds (which enhance the surface fluxes) are found and where $\hat{h}$ is large; it is near zero at the center of the TC because the winds are calmer there (Fig. 4e). There are some areas in the environment away from the TC where the surface flux feedback is slightly negative (tending to damp $\hat{h}$ anomalies). This is because surface enthalpy fluxes depend both on surface wind speed and air-sea enthalpy disequilibrium, and the two influences generally oppose each other (Wing et al. 2016). The advective term is negative, indicating that advection of $\hat{h}$ damps $\hat{h}$ anomalies (Fig. 4f). Equivalent figures and animations for the other five models are provided in the supplemental material.

Across all models, although to a lesser extent in FLOR and GEOS, the surface flux feedback is positive near the TC and becomes larger as the TC approaches the LMI (Fig. 5, right column). The radiative feedback is also positive across all models but, with the exception of GEOS, is smaller than the surface flux feedback. It also generally increases with intensification toward the LMI, though the relative rate of increase is slower than that of the surface flux feedback (Fig. 5, left column). The feedback terms generally increase with intensification because the anomalously high values of moist static energy, surface fluxes, and cloud-induced reduction in radiative cooling increase as the TC develops and matures. While the azimuthal mean structure of these feedback terms is similar across all models, there are 

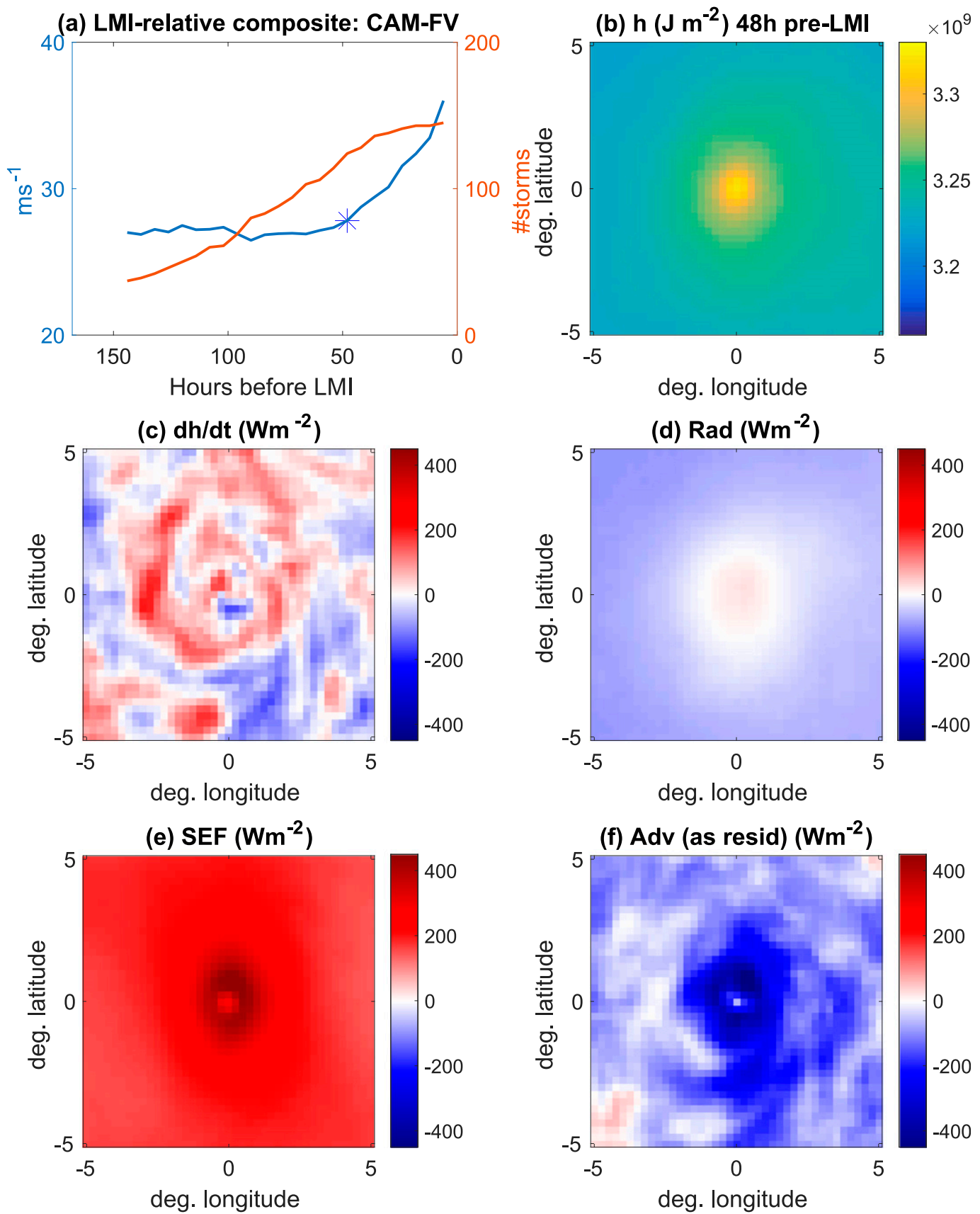

FIG. 3. Composite $48 \mathrm{~h}$ prior to LMI of the moist static energy budget of all TCs in CAM-FV. (a) The composite mean TC intensity (blue line) and number of storms in the composite (red line) as a function of time relative to LMI; the star indicates the time at which the rest of the panels are valid. The (b) column-integrated MSE, (c) MSE tendency, (d) column radiative flux convergence, (e) surface enthalpy flux, and (f) MSE advection are also shown as a function of latitude and longitude relative to the TC center.

notable differences in their strengths (e.g., Fig. 5f). The models that produce stronger storms, both overall and at the time of the composite, have stronger feedbacks (CAM-SE, CAM-FV, and HiRAM), especially with regard to the surface flux feedback.
One possible explanation for the differences in the magnitudes of feedbacks across the models is that they may simply have different absolute values of moist static energy and its variability (which can be seen in the versions of Figs. 3 and 4 for the other models in the 

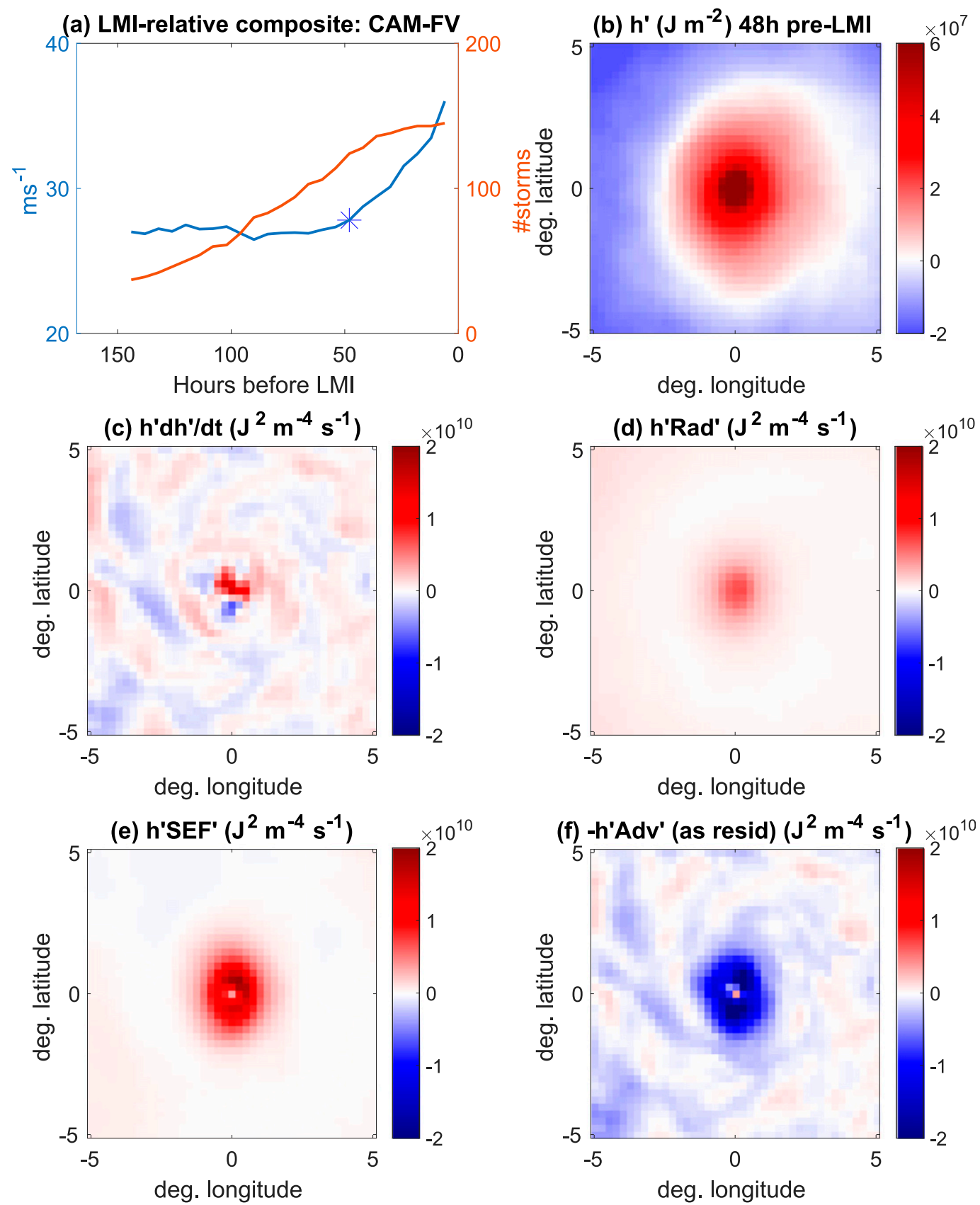

FIG. 4. Composite $48 \mathrm{~h}$ prior to LMI of the moist static energy variance budget in CAM-FV. (a) The composite mean TC intensity (blue line) and number of storms in the composite (red line) as a function of time relative to LMI; the star indicates the time at which the rest of the panels are valid. The (b) column-integrated MSE anomaly from the box mean, (c) MSE variance tendency, (d) radiative feedback, (e) surface flux feedback, and (f) advective feedback are also shown as a function of latitude and longitude relative to the TC center.

supplemental material). To adjust for this, we normalize the feedback terms by the value of the box average $\hat{h}$ variance at a given time, and then perform the composite. An example of this analysis, for the azimuthal mean of the composite of normalized radiative and surface flux feedbacks $96,72,48$, and $24 \mathrm{~h}$ prior to LMI, is shown in Fig. 6 (latitude/longitude spatial plots at these and other times are shown in movies in the supplemental material). The differences between models remain, particularly in the surface flux feedback. There are minimal model-model differences in the radiative feedback, which indicates that the radiative feedback is 

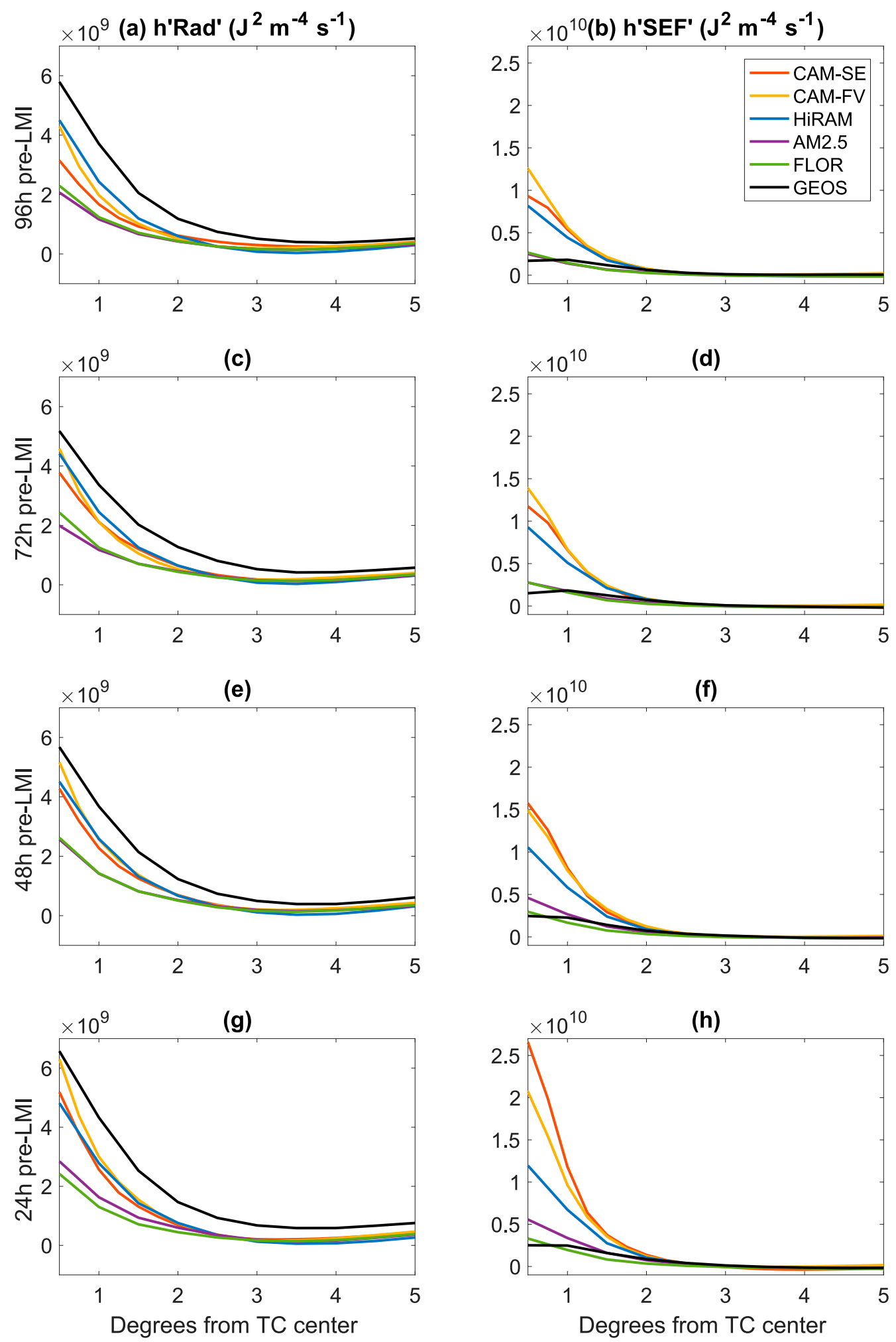

FIG. 5. Azimuthal mean of composite of (left) radiative and (right) surface flux feedbacks (a),(b) 96, (c),(d) 72, (e),(f) 48, and (g),(h) $24 \mathrm{~h}$ prior to LMI, in CAM-SE (red), CAM-FV (orange), HiRAM (blue), AM2.5 (purple), FLOR (red), and GEOS (black) simulations. Note that the axes are different for the left and right columns. 


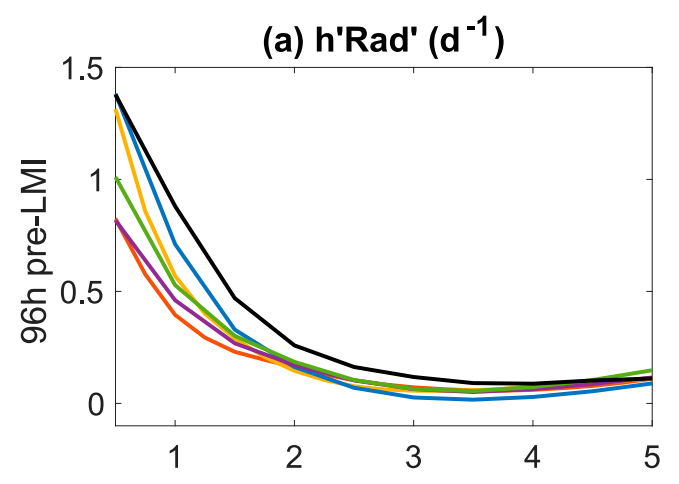

(c)

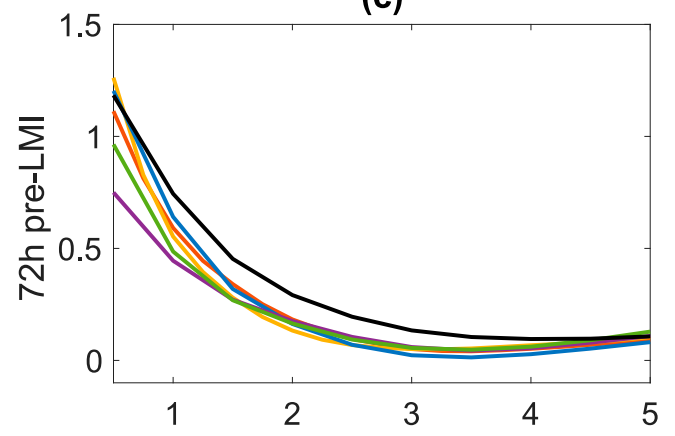

(e)

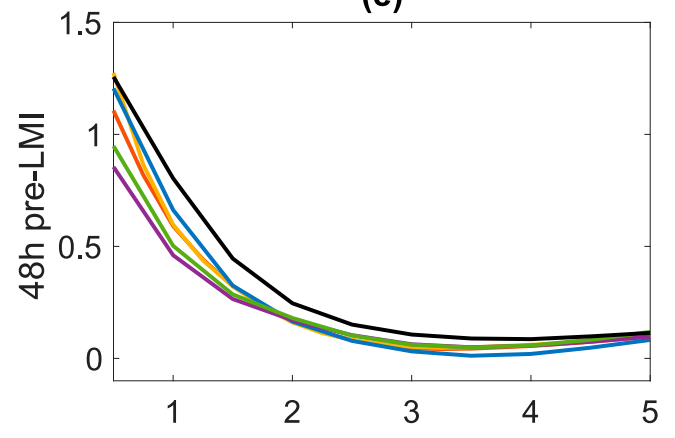

(g)

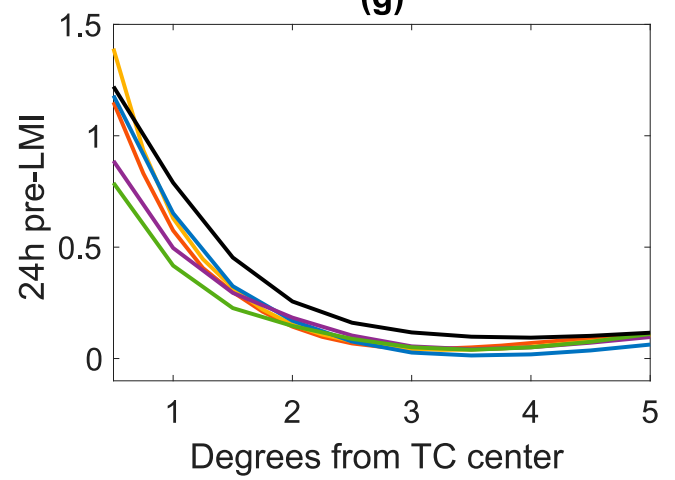

(b) h'SEF' $\left(d^{-1}\right)$

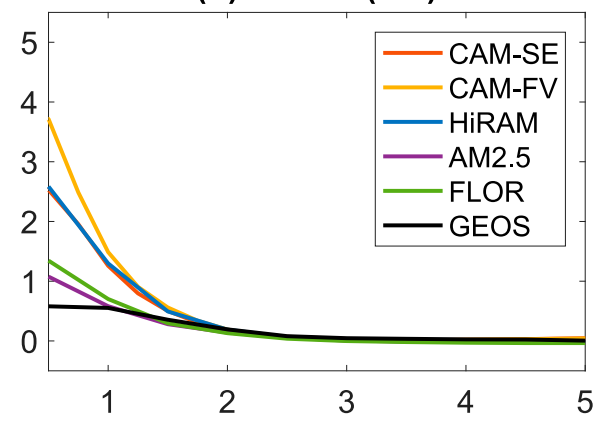

(d)

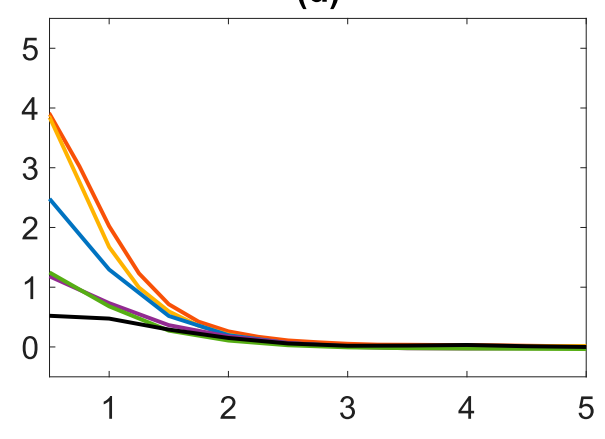

(f)

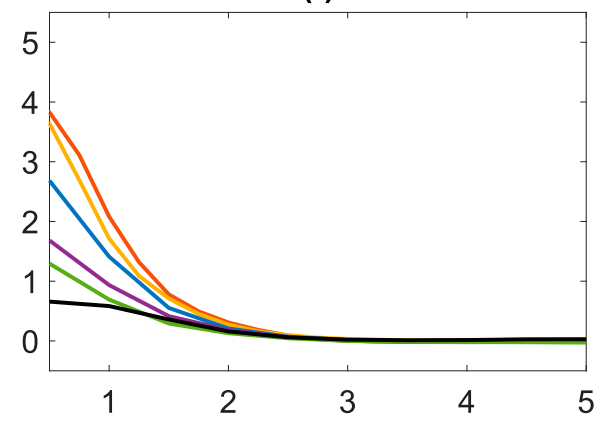

(h)

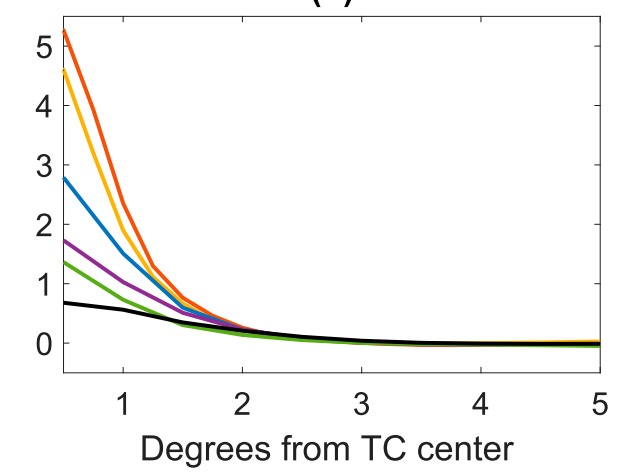

FIG. 6. Azimuthal mean of composite of normalized (left) radiative and (right) surface flux feedbacks (a),(b) 96 , (c),(d) 72, (e),(f) 48, and (g),(h) $24 \mathrm{~h}$ prior to LMI, in CAM-SE (red), CAM-FV (orange), HiRAM (blue), AM2.5 (purple), FLOR (red), and GEOS (black) simulations. The feedbacks are normalized by the box-mean $\hat{h}$ variance. Note that the axes are different for the left and right columns. 
relatively more important in the models with weaker surface flux feedbacks and weaker storms (AM2.5, FLOR, and GEOS).

\section{d. Box-average variance budget}

The above analysis shows the contribution of different terms to the $\hat{h}$ variance for the azimuthal mean as a function of distance from the TC center, but it is also informative to examine the box-average budget. This is computed, for each TC and track point, by averaging the squared $\hat{h}$ anomalies and each term in the variance budget over the box surrounding the TC, and then taking a composite over the same time relative to LMI. The composite box-average $\hat{h}$ variance generally increases as the LMI is approached (Figs. 7a-f), although individual TCs do not always have a monotonic increase in $\hat{h}$ variance over their life cycle (in part because individual TCs do not always have a monotonic increase in intensity). This provides evidence for the relevance of the $\hat{h}$ variance budget for TC intensification. We find that an increase in the box-average $\hat{h}$ variance with TC formation and intensification is more robust in the stronger TCs. Therefore, for the calculation of the life cycle composite box-average $\hat{h}$ variance budget, we restrict our analysis to the storms whose LMI is in the upper quartile of the LMI distribution (Fig. 7).

The evolution of the terms in the box-average $\hat{h}$ variance budget throughout the TC life cycle is qualitatively similar across the models and similar to the behavior of an idealized TC in cloud-resolving simulations (Wing et al. 2016). The surface flux and longwave radiative feedback are the two main contributors to increases in box-average $\hat{h}$ variance. Early in the TC life cycle as the TC is forming, the two have similar magnitudes, but as the TC develops and intensifies toward its LMI, the surface flux feedback increases substantially (as a result of the increasing surface wind speed, which drives higher surface fluxes near the TC). This is apparent in the HiRAM, CAM-SE, and CAM-FV simulations (which have the strongest TCs) and consistent with the results of Wing et al. (2016). In the other models, the surface flux feedback increases only slightly, if at all. In FLOR and GEOS (which have the weakest TCs), the boxaverage surface flux feedback is actually smaller than the longwave radiative feedback throughout the composite TC life cycle. These results indicate that not only do the values of the feedback terms differ from model to model, but so does the relative importance of a given feedback compared to the other feedbacks. Across all models, the shortwave feedback is very small (so the radiative feedback is dominated by spatial variability in the longwave cooling) and the advection (residual) term is negative.
As measured by the mean LMI over all TCs in an individual model, the models that simulate more intense storms have larger box-average surface flux feedbacks (Fig. 8; shown for the composite $48 \mathrm{~h}$ prior to LMI, but the results are similar at other times). The box-average radiative feedback, on the other hand, does not vary much across models. It follows that the models with stronger storms have a higher ratio of composite mean box-average surface flux feedback to radiative feedback (Fig. 8b). That is, while both surface flux and radiative feedbacks contribute to increased $\hat{h}$ variance and TC development in all models, the surface flux feedback contributes relatively more in the models with stronger storms. This points to the importance of spatially varying surface fluxes (primarily driven by wind speed variability) for the simulation of TCs.

We note in passing that one potential limitation of this analysis is that the same sized-box was used for all six models and for all TCs in each model. Unlike idealized simulations where there is one TC in a homogenous domain (Wing et al. 2016), in these realistic simulations, a box size must be chosen such that it is large enough to contain the TC as well as the environment surrounding it, but not so large that it contains other disturbances. While a larger or smaller box may be more appropriate for larger or smaller TCs (and the minimum TC size is limited by the grid resolution) we found a fixed $10^{\circ} \times$ $10^{\circ}$ box size to be a good compromise.

\section{e. Composite over intensity bins}

While the life cycle composite discussed in sections $4 \mathrm{~b}-4 \mathrm{~d}$ is useful for examining how different feedbacks contribute to the increase in $\hat{h}$ variance throughout the TC life cycle in each model, the difference in feedback magnitudes across the models could also be an artifact of the fact that although the composite is taken at the same stage in the TC life cycle, the intensities at that time are different (compare, for example, the red line in the first row of Fig. 7). The surface flux feedback explicitly depends on the TC intensity because of the dependence of surface fluxes on surface wind speed. Therefore, we also analyze an intensity-bin composite, as described in section 3 .

Despite being compared at the same TC intensities, there are differences in the moist static energy and its sources and sinks across the models (Figs. 9a-c). GEOS stands out by having noticeably smaller values of moist static energy overall and stronger radiative cooling (more negative) in the environment around the TC (Figs. 9d-f). The other models look fairly similar to each other, in terms of the radial structure, with the biggest difference being in the strength of the surface fluxes near the center of the TC. CAM-SE has the 
(a) CAM-SE

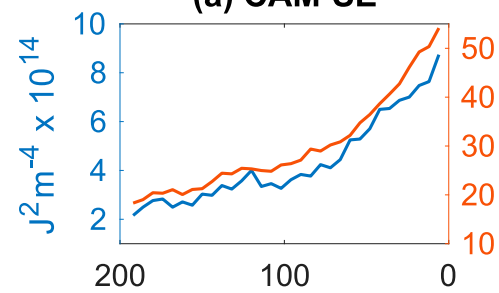

(c) CAM-FV

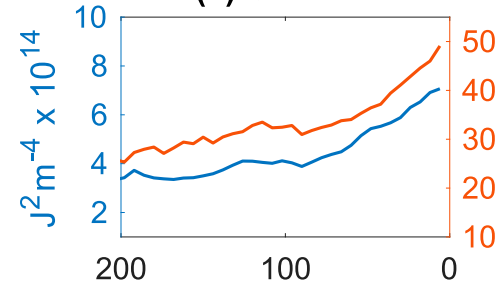

(e) HiRAM

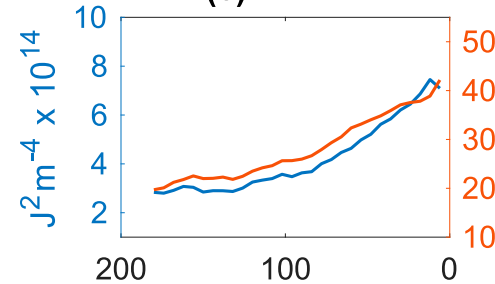

(g) AM2.5

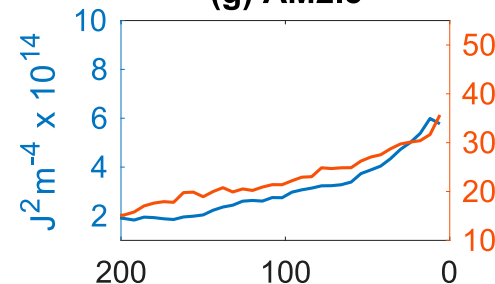

(i) FLOR

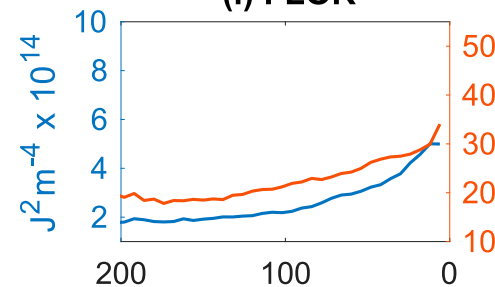

(k) GEOS

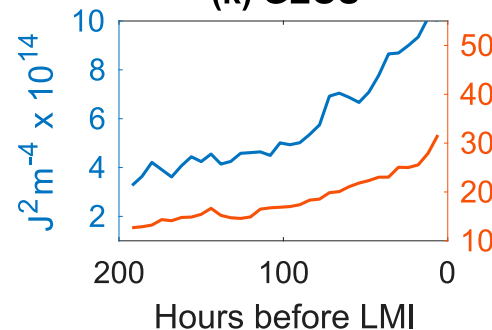

$0^{9}$ (b) CAM-SE
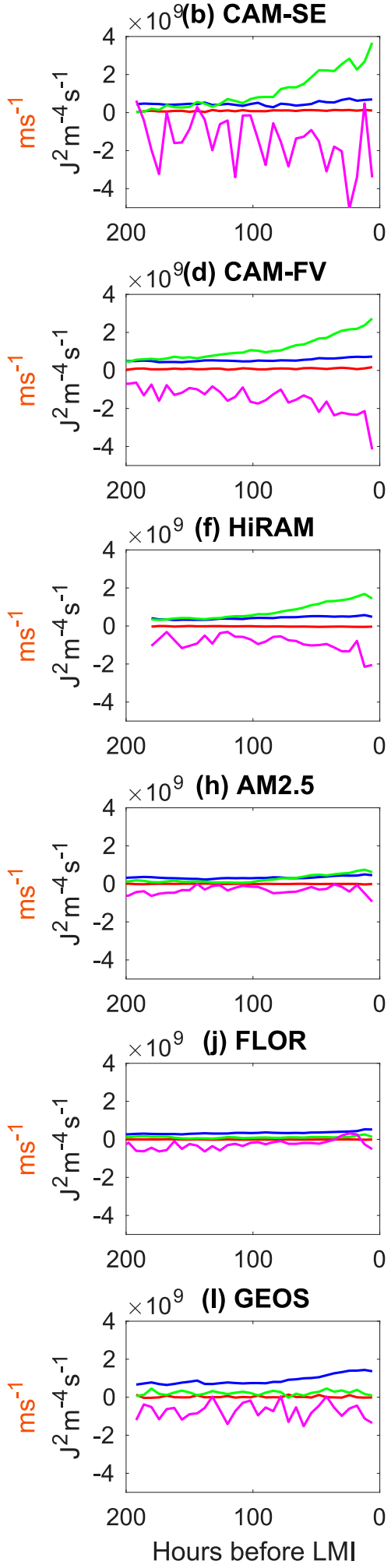

FIG. 7. Composite of the box-average MSE variance budget in the (a),(b) CAM-SE, (c),(d) CAM-FV, (e),(f) HiRAM, (g),(h) AM2.5, (i),(j) FLOR, and (k),(l) GEOS simulations. (left) As a function of time relative to LMI, the composite mean TC intensity (red line; right axis) and the box-average MSE variance (blue line; left axis), scaled by $10^{14}$. (right) As a function of time relative to LMI, the surface flux (green line), longwave (blue line), shortwave (red line), and advective (pink line) feedbacks. The composite is over all TCs that have a LMI in the upper quartile of the LMI distribution. 

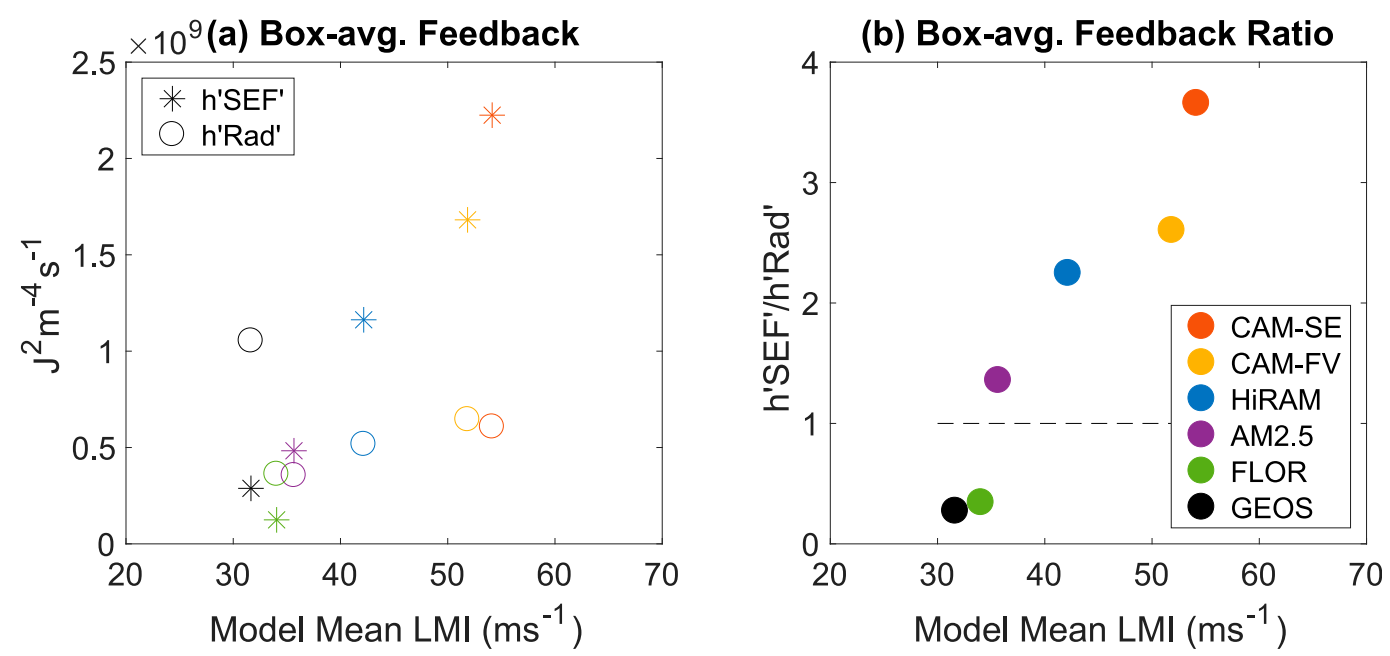

FIG. 8. (a) The composite of the box-average surface flux (asterisks) and longwave radiative feedback (open circles) at $48 \mathrm{~h}$ prior to LMI for each model as a function of that models mean LMI. (b) The ratio of the composite box-average surface flux and radiative feedbacks for each model. Model mean LMI is defined as the average LMI of all TCs that have LMI in the upper quartile of the LMI distribution. In all panels, the models are CAM-SE (red), CAM-FV (yellow), HiRAM (blue), AM2.5 (purple), FLOR (green), and GEOS (black). The composite is over all TCs that have a LMI in the upper quartile of the LMI distribution.

strongest surface fluxes, followed by CAM-FV, HiRAM, AM2.5, GEOS, and then FLOR (Figs. 9h-j). There are also slight differences in the radiative cooling; the reduced radiative cooling associated with thick cloud cover over the TC is spread over a larger area in HiRAM, AM2.5, and FLOR (Figs. 9d-f). This could be related to the coarser resolution of these models compared to CAM-SE and CAM-FV.

The different spatial structures of moist static energy, radiative cooling, and surface fluxes in Fig. 9 are reflected in model-model differences in the feedback terms in the $\hat{h}$ variance budget, shown for three different intensity bins in Fig. 10. The structure of $\hat{h}^{2}$ and the feedback terms is similar across the intensity bins, but the magnitude generally increases with intensity. The main conclusion from Fig. 10 is that even when composited over the same intensities, there are notable differences in the strength of the azimuthal-mean surface flux feedback between models. The surface flux feedback near the center of the TC is strongest in CAM-SE, CAM-FV, and HiRAM, which are the models that simulated the strongest TCs, followed by AM2.5, GEOS, and FLOR (Figs. 10h-j). The interpretation of this result is that, at a given intensity, certain models have a stronger surface flux feedback than others, which favors further amplification of $\hat{h}$ anomalies and further intensification of the TC, to the extent that $\hat{h}$ and surface winds are related. With the exception of GEOS, which has a notably strong radiative feedback, the radiative feedbacks are similar across the models (Figs. 10d-f). These results are unchanged when each term has been normalized by the box-mean $\hat{h}$ (shown in the supplemental material).

The value of the intensity-bin composite is made clear in Fig. 11, which shows the box-average $\hat{h}$ variance and surface flux and radiative feedbacks composited over each $3 \mathrm{~m} \mathrm{~s}^{-1}$ intensity bin. There is a clear tendency for the $\hat{h}$ variance to be higher at higher wind speeds, although the absolute value of $\hat{h}$ variance differs across models, especially in GEOS (Fig. 11a). This provides additional evidence that $\hat{h}$ variance is a good proxy for TC intensity. Further, the rate of increase of $\hat{h}$ variance with intensity is similar across all models, indicating that the models have a similar "efficiency" in converting $\hat{h}$ variance increases to intensification and that the intermodel spread in intensity is instead due to differences in the strengths of the feedbacks that are a source of $\hat{h}$ variance. There is a strong dependence of the surface flux feedback on the wind speeds over which it is composited, with the higher-intensity bins having surface flux feedbacks that are 2-3 times stronger than the lower-intensity bins (Fig. 11b). The radiative feedback, on the other hand, is only weakly dependent on the wind speed over which it is composited (Fig. 11c). The surface flux feedback in CAM-SE and CAM-FV is similar across most intensity bins, while the radiative feedback in CAM-FV becomes larger above the $30 \mathrm{~m} \mathrm{~s}^{-1}$ bin. This reflects the fact that the overall TC intensity distributions in CAM-SE and CAM-FV are similar; while CAM-FV has an LMI distribution that is shifted toward stronger storms (Fig. 2a), CAM-SE has an overall higher probability of TC snapshots at higher intensities 

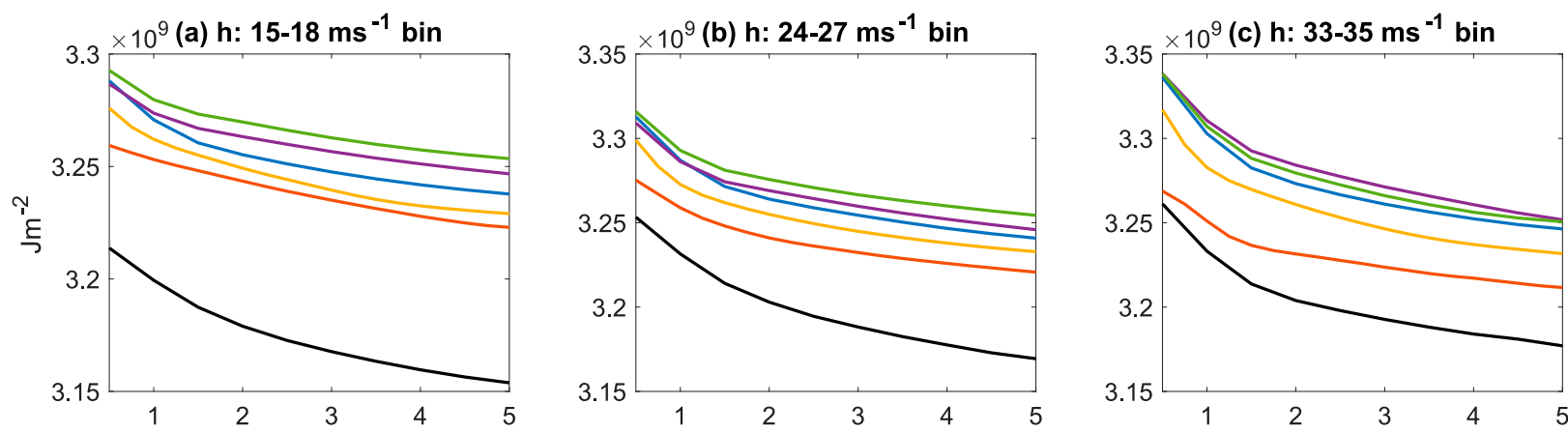

(d) Rad

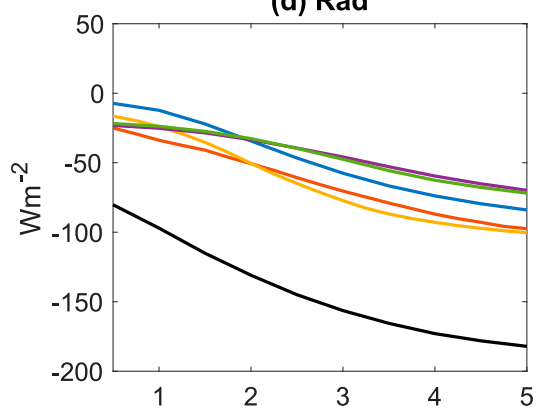

(g) SEF

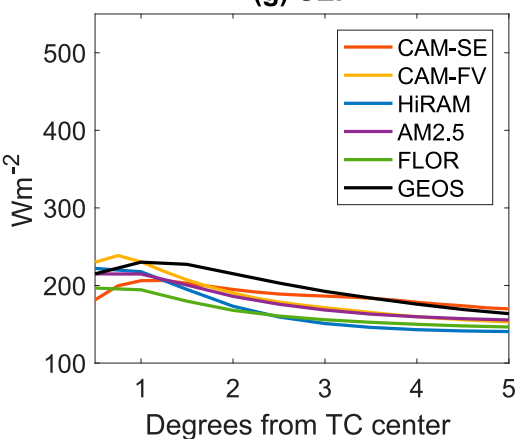

(e) Rad

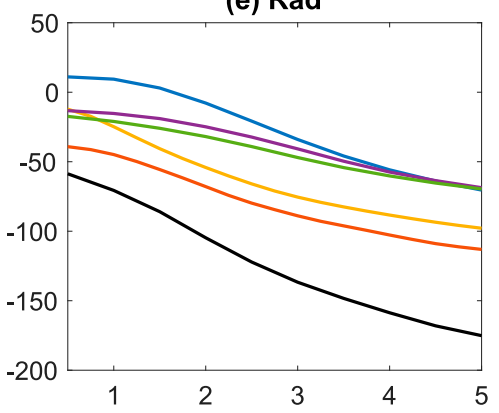

(h) SEF

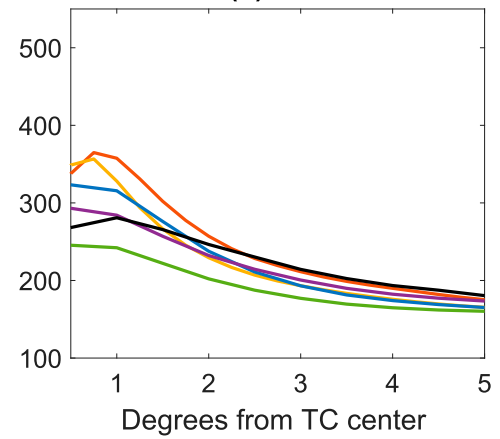

(f) Rad

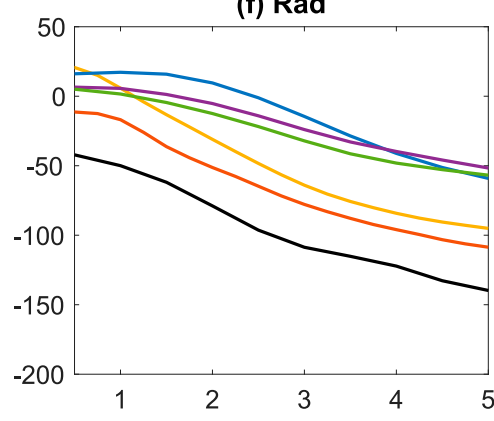

(i) SEF

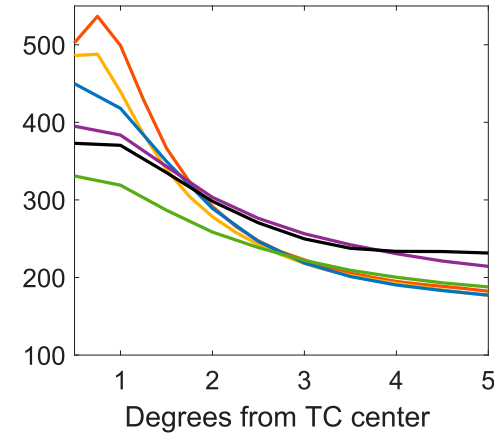

FIG. 9. Azimuthal mean of intensity bin composite of (a)-(c) column-integrated MSE ( $\mathrm{J} \mathrm{m}^{-2}$ ), (d)-(f) column radiative flux convergence $\left(\mathrm{W} \mathrm{m}^{-2}\right)$, and (g)-(i) surface fluxes $\left(\mathrm{W} \mathrm{m}^{-2}\right)$ in the (left) $15-18 \mathrm{~m} \mathrm{~s}^{-1}$ bin, (center) $24-27 \mathrm{~m} \mathrm{~s}^{-1}$ bin, and (right) $33-35 \mathrm{~m} \mathrm{~s}^{-1}$ bin, in the CAM-SE (red), CAM-FV (orange), HiRAM (blue), AM2.5 (purple), FLOR (red), and GEOS (black) simulations.

(Fig. 2b). Between 20 and $35 \mathrm{~m} \mathrm{~s}^{-1}$, AM2.5 has a notably stronger surface flux feedback than FLOR (Fig. 11a); recall that AM2.5 simulates more intense TCs than FLOR does (Fig. 2). Above the $25 \mathrm{~m} \mathrm{~s}^{-1}$ bin, HiRAM has a significantly stronger surface flux feedback than AM2.5, suggesting that this allows the TCs in HiRAM to eventually become stronger than those in AM2.5. GEOS is a bit of an outlier; while the relatively weak surface flux feedback is consistent with the fact that GEOS simulates weaker TCs, the radiative feedback and $\hat{h}$ variance itself are much stronger than in the other models.

These results are summarized in Fig. 11d, which shows both the box-average surface flux and radiative feedbacks composited over the $24-27 \mathrm{~m} \mathrm{~s}^{-1}$ bin in each of the models. There is a clear tendency for the box-average surface flux feedback to be larger in the models that simulate TCs with higher mean LMI, while the radiative feedback does not vary much between models.

\section{Discussion}

There are several informative comparisons that can be made by comparing individual pairs of models in the set of six examined here. CAM-SE and CAM-FV differ primarily in their dynamical core, which has been shown 

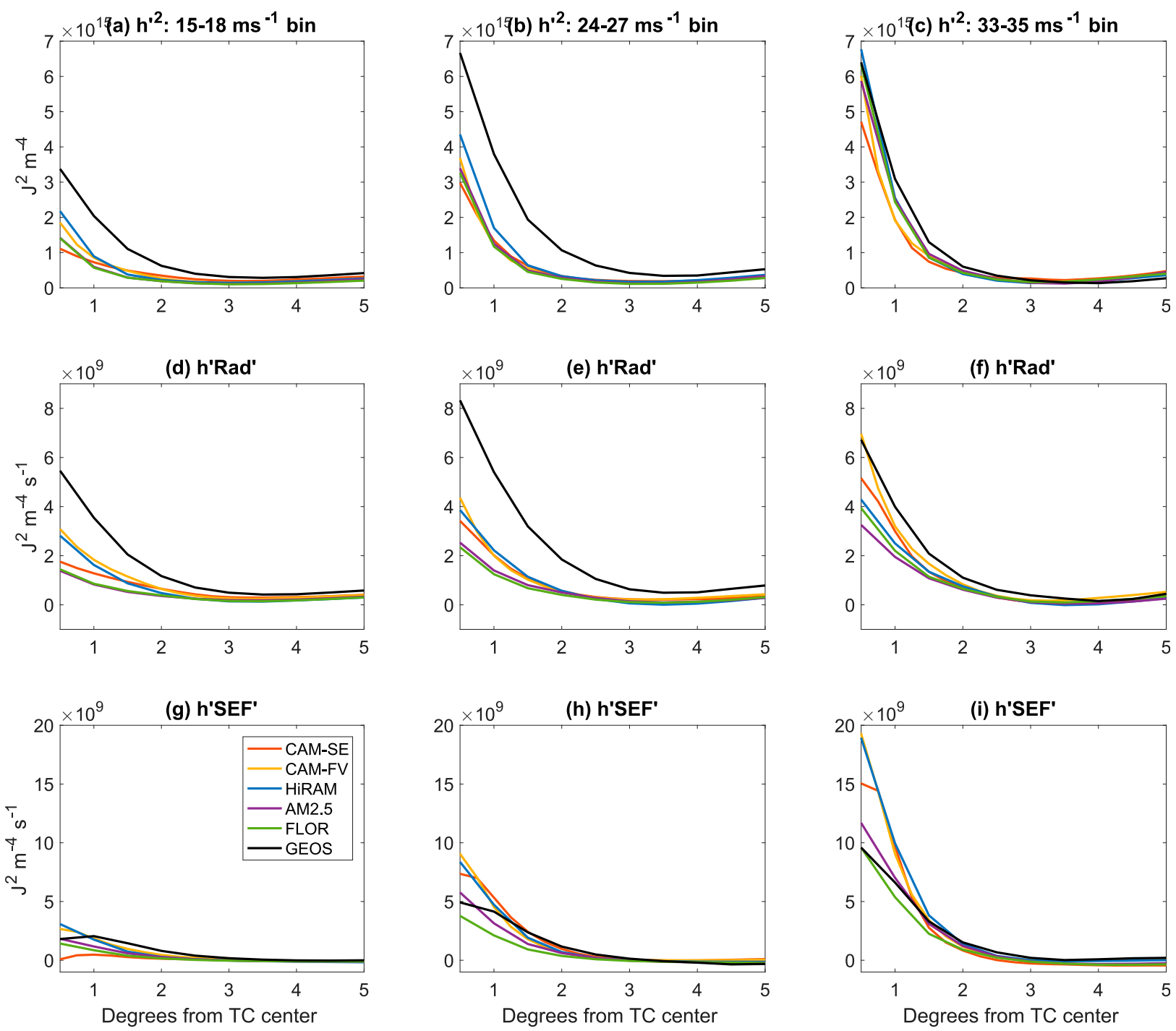

FIG. 10. Azimuthal mean of intensity bin composite of (top) MSE variance $\left(\mathrm{J}^{2} \mathrm{~m}^{-4}\right)$, (d)-(f) radiative feedback $\left(\mathrm{J}^{2} \mathrm{~m}^{-4} \mathrm{~s}^{-1}\right)$, and $(\mathrm{g})-(\mathrm{i})$ surface flux feedback $\left(\mathrm{J}^{2} \mathrm{~m}^{-4} \mathrm{~s}^{-1}\right)$ in the (left) $15-18 \mathrm{~m} \mathrm{~s}^{-1}$ bin, (center) 24-27 m s $\mathrm{m}^{-1}$ bin, and (right) $33-35 \mathrm{~m} \mathrm{~s}^{-1}$ bin, in the CAM-SE (red), CAM-FV (orange), HiRAM (blue), AM2.5 (purple), FLOR (red), and GEOS (black) simulations.

to affect simulated TC intensity and frequency, with the spectral element core producing stronger TCs (Reed et al. 2015). In the simulations we examined, the distribution of LMI in CAM-SE was wider than that in CAM-FV, with a higher relative frequency of both weak and strong storms (Fig. 2a). However, the comparison between CAM-SE and CAM-FV presented here is not an apples-to-apples comparison because the CAM-SE distribution includes only storms in the North Atlantic (which may have weaker storms than other basins, such as the western North Pacific), includes different years than the CAM-FV simulation, and uses a different tracking algorithm. When TCs in the North Atlantic in 1996-97 are analyzed for both CAM-SE and CAM-FV, the TCs in CAM-SE are found to reach higher intensity more frequently (Y. Moon et al. 2019, manuscript submitted to J. Climate), consistent with Reed et al. (2015). We showed that CAM-SE tends to have a stronger surface flux feedback than CAM-FV near the center of the TC within $48 \mathrm{~h}$ of the time of LMI and that, when storms in the upper quartile of the LMI distribution are considered, the box-average surface flux feedback is also larger in CAM-SE. The surface flux feedback was also found to be slightly stronger in CAM-SE than CAM-FV when considering a composite at the same intensity.

HiRAM and AM2.5 differ only in their choice of convection scheme, and HiRAM simulates notably stronger TCs than AM2.5 (Fig. 2). Kim et al. (2018) 

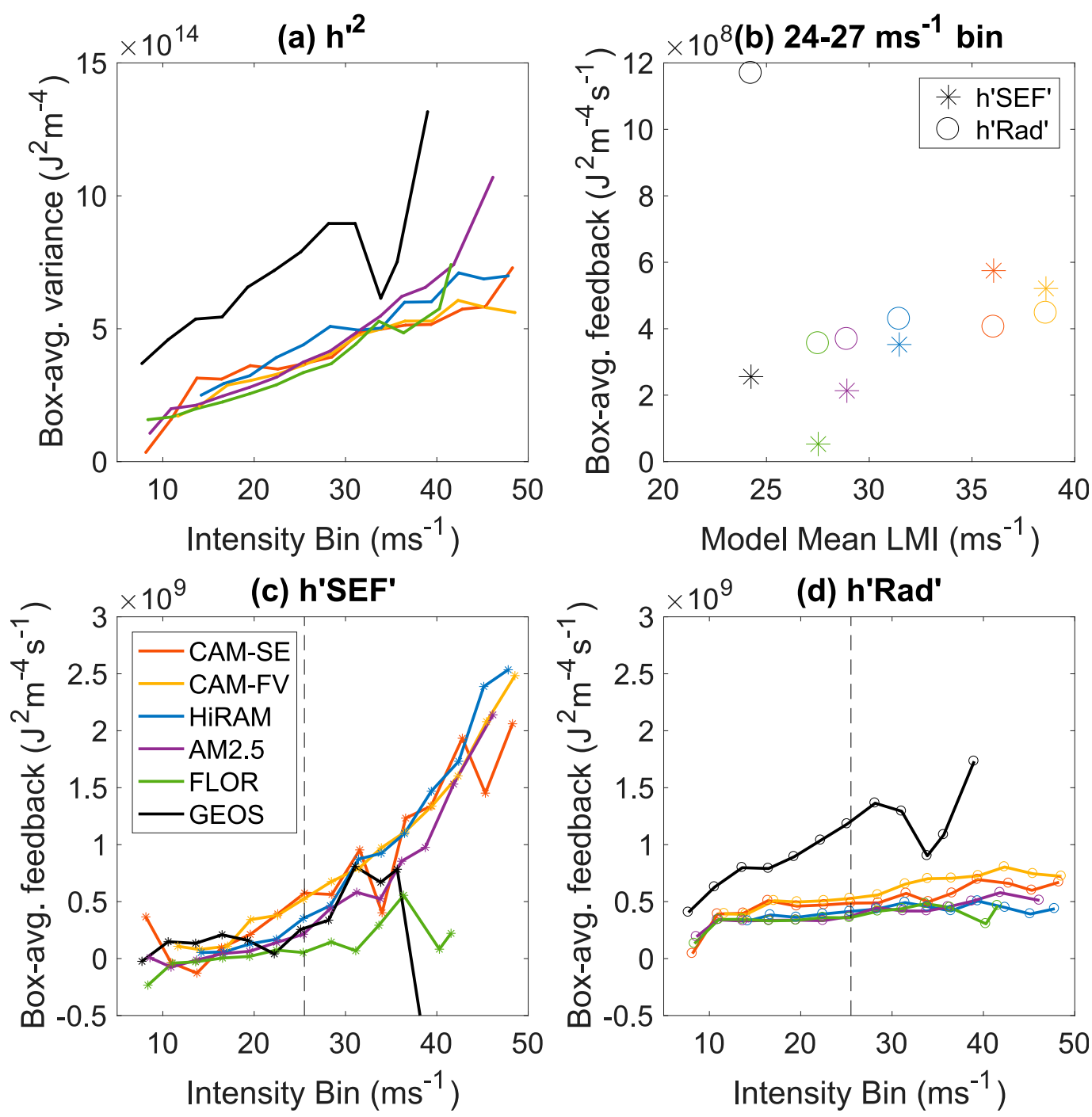

FIG. 11. (a) Box-average MSE variance and (c) surface flux and (d) radiative feedback terms in the MSE variance budget composited over intensity bins. The $x$ axis in (a), (c), and (d) indicates the mean intensity in each bin, for each model. (b) The box-average surface flux (asterisk) and radiative (open circle) feedback terms composited over the $24-27 \mathrm{~m} \mathrm{~s}^{-1}$ bin [indicated by the dashed lines in (c) and (d)] for each model, as a function of the mean LMI of simulated TCs in that model.

linked this to both larger surface fluxes and greater rainfall amounts (and therefore diabatic heating) in the inner-core regions of TCs in HiRAM compared to AM2.5. This is consistent with our analysis, in which the surface flux feedback was notably stronger in HiRAM than in AM2.5, both at the same stage in the TC life cycle and at the same intensity. The radiative feedback was found to be slightly stronger in HiRAM, although the difference was small compared to the difference in surface fluxes.

AM2.5 and FLOR differ only in that FLOR is a coupled ocean-atmosphere model, while AM2.5 is an atmosphere-only model. AM2.5 simulates stronger TCs than FLOR (Fig. 2), and this too appears to be linked to a stronger surface flux feedback in in AM2.5. Ocean coupling is known to reduce TC intensity, because the cold wake generated by TC-driven upwelling is a negative feedback on the TC (e.g., Lloyd and Vecchi 2011; Zarzycki 2016; Zarzycki et al. 2016; Scoccimarro et al. 2017). Here, we show explicitly that ocean coupling also reduces the surface flux feedback, as defined in the $\hat{h}$ variance framework. This is significant because, in the context of convective self-aggregation, these surface flux feedbacks have only been examined in simulations with fixed SST (e.g., Wing and Emanuel 2014; Coppin and Bony 2015; Wing and Cronin 2016). The reduction in the 
surface flux feedback with ocean coupling is consistent with studies that have found that ocean coupling delays self-aggregation (Hohenegger and Stevens 2016).

Why would the surface flux feedback differ across models? In general, the sign and magnitude of the surface flux feedback depend on the spatial covariability of column-integrated moist static energy and surface fluxes. The spatial variability of surface fluxes in turn depends on the spatial variability in surface wind speed and air-sea enthalpy disequilibrium. Therefore, this feedback could be larger in a given model because of 1) higher moist static energy near the TC and/or lower moist static energy in the surrounding environment, 2) larger values of surface fluxes near the center of the TC because of stronger winds or larger air-sea disequilibrium (although the latter is unlikely to be large near the center of the TC), or 3 ) better alignment between the location of the high values of surface fluxes (usually near the strongest winds) and the location of highest moist static energy. Even when evaluated at the same intensity, the overall structure of the TC wind field may be different across different models. Differences in the representation of boundary layer processes or frequency of coupling to the surface could lead to different surface fluxes, and differences in the representation of moist convection could lead to different patterns of humidity.

With regards to CAM-SE and CAM-FV, Fig. 9 indicates that the surface fluxes themselves are larger near the TC center in CAM-SE. Y. Moon et al. (2019, manuscript submitted to J. Climate) found that this is mostly due to a difference in the latent heat flux, and that this was mostly due to a larger air-sea enthalpy disequilibrium in CAM-SE. It is not clear what about the different dynamical cores could cause this difference, but one possibility is a difference in how the physics-dynamics coupling is configured. More generally, differences in divergence damping have also been proposed as a reason for the sensitivity of TC simulation to dynamical core (Zhao et al. 2012).

GEOS, which has similar horizontal resolution as HiRAM, AM2.5, and FLOR, simulates the weakest storms and the weakest surface flux feedback compared to other models when compared at the same intensity. But GEOS has a larger (more positive) radiative feedback than the other models, both when compared at the same intensity and at the same stage in the TC life cyclewhich is a difference in the opposite direction of one that would explain the weaker storms. We speculate that the difference in radiative feedback originates from details in the convection and cloud schemes (such as cloud lifetimes and detrainment) or possible mean state differences, but an in-depth investigation is beyond the scope of this study. We also note that, when the $15.2 \mathrm{~m} \mathrm{~s}^{-1}$ threshold is applied, GEOS has many fewer storms than the other models (and observations). This is consistent with Lim et al. (2015), who found that realistic numbers of TCs were difficult to achieve with $0.5^{\circ}$ grid spacing without modifying the values for TC detection.

The life cycle composites (sections $4 \mathrm{c}$ and $4 \mathrm{~d}$ ) also indicate that, in TCs simulated by high-resolution GCMs, the radiative feedback is at least as important as the surface flux feedback in the early stages of TC development, and in some models, it remains as important throughout intensification to LMI. This result adds to a growing body of evidence on the importance of radiation in TC formation, intensification, and structure (Fovell et al. 2010; Bu et al. 2014; Melhauser and Zhang 2014; Nicholls 2015; Navarro and Hakim 2016; Tang and Zhang 2016; Fovell et al. 2016; Wing et al. 2016; O'Neill et al. 2017; Bu et al. 2017). It is consistent with the cloudresolving model results of Wing et al. (2016), who found a similar role for the radiative feedback in the evolution of a spontaneously generated TC in radiativeconvective equilibrium simulations, and found that removal of radiative feedbacks inhibits or significantly delays the onset of genesis. The positive radiative feedbacks diagnosed in this study result from the direct effect of differential heating between the area of deep convection in the developing TC and the surrounding drier environment, which acts to favor ascent and moistening in the already moist area. This promotes clustering of convection and continued moistening of the atmosphere, both of which further the formation of a tropical cyclone. The differential heating can also indirectly favor TC formation by the generation of a circulation response (Nicholls 2015; Muller and Romps 2018), although this is not explicitly quantified by our $\hat{h}$ variance budget diagnostic. Our results indicate that it is specifically the variability in longwave radiation due to clouds (Fig. 7) that drives the positive radiative feedback.

\section{Conclusions}

We have developed and applied process-oriented diagnostics utilizing budgets of column moist static energy and the spatial variance of column moist static energy to tropical cyclones in six high-resolution climate models. These diagnostics allow us to quantify different feedbacks related to how convection, moisture, clouds, and related processes are coupled.

We found that the general evolution of the moist static energy variance budget along the composite TC life cycle is qualitatively similar to that found in idealized cloud-resolving model simulations. The box-average moist static energy variance is higher at higher wind 
speeds, both in the life cycle and intensity-bin composites. Surface flux and radiative feedbacks both contribute positively, and fairly equally, to an increase in moist static energy variance in the early stages of TC formation and intensification. As the TC nears its lifetime maximum intensity, the surface flux feedback increases beyond the magnitude of the radiative feedback (which is dominated by longwave cloud effects) in most, though not all models. At the same point in the TC life cycle, the models that simulate stronger storms have stronger surface flux feedbacks, while the radiative feedback is more consistent across models. This indicates that the radiative feedbacks are relatively more important to TC development in models with weak storms. The difference in surface flux feedback across the models is robust even when we consider composites over the same intensity.

In particular, CAM-SE and CAM-FV simulate the strongest storms and have the strongest surface flux feedbacks, and are even slightly different from each other despite the only difference being the dynamical core. HiRAM has notably stronger storms and stronger surface flux feedbacks than do AM2.5 or FLOR, despite all three models being at the same resolution and using same dynamical core-indicating the importance of physics parameterizations, especially the convection scheme, as has also been noted by other studies. AM2.5 has stronger storms and a stronger surface flux feedback than FLOR, indicating that ocean coupling reduces the strength of the surface flux feedback. GEOS has the weakest storms and weakest surface flux feedback, but, curiously, a stronger than average radiative feedback.

The intermodel spread in surface flux feedbacks results from a difference in the spatial covariability in moist static energy, surface wind speed, air-sea disequilibrium, and surface enthalpy fluxes between the different models, which is linked to the model representation of the spatial structure of the TC wind and moisture field. Overall these results indicate that the representation of the interaction of spatially varying surface fluxes with the developing TC is partially responsible for intermodel spread in TC simulation, in which stronger variability of surface fluxes between the TC core and its surroundings leads to stronger TCs. Our results also indicate that the radiative feedback contributes to TC development across all models, especially at weaker intensities or in earlier stages of development.

These results show that the moist static energy variance budget is a useful tool for examining tropical cyclone intensification in models, with links to the actual physical processes responsible for model simulation of TCs. However, while it is able to distinguish between models, there does not yet exist an observational "reference" version of this diagnostic, so it is unknown which models' representation of surface flux and radiative feedbacks is "correct." Creating a reference diagnostic from observations of TCs, as well as applying this diagnostic to a broader range of models, will be the subject of future work.

Acknowledgments. This work is a contribution to the process-oriented diagnostic effort of the NOAA MAPP Model Diagnostics Task Force. This study was supported by NOAA's Climate Program Office's Modeling, Analysis, Predictions, and Projections program through Grants NA15OAR4310087, NA15OAR4310095, NA18OAR4310270, NA18OAR4310276, and NA18OAR4310277. Initial work on this study was performed while A. Wing was supported by a NSF AGS Postdoctoral Research Fellowship (AGS-1433251). Y. Moon was supported in part by a NSF AGS Postdoctoral Research Fellowship (AGS-1524270). D. Kim was also supported by the National Aeronautics and Space Administration's Modeling, Analysis, and Prediction program under Grant 80NSSC17K0227, the U.S. Department of Energy's Regional and Global Model Analysis program under Grant DE-SC0016223, and the Korean Meteorological Administration Research and Development Program under Grant KMI2018-03110. We thank Salvatore Pascale and Lucas Harris for helpful feedback on the manuscript, and Martin Singh and two anonymous reviewers for constructive comments and suggestions. We thank Michael Bosilovich for facilitating access to the GEOS M2-AMIP data and providing additional information about the simulation. The M2-AMIP data are now publicly available through the NASA Center for Climate Simulation (NCCS) DataPortal (https:// portal.nccs.nasa.gov/datashare/gmao_m2amip/).

\section{APPENDIX}

\section{Details of Moist Static Energy Budget Formulation}

\section{a. Column integral}

We perform our analysis on model levels using the 4D varying pressure calculated using the surface pressure and the appropriate relation for each model's hybrid vertical coordinates. Usually, one would perform the vertical integral of moist static energy (MSE) in Eq. (A1) using the surface pressure as $p_{b}$. However, the surface pressure decreases dramatically over the life cycle of a tropical cyclone, which complicates the calculation of the column integral and interpretation of the MSE and MSE variance budgets. When integrating over the entire column, the column-integrated MSE of the tropical cyclone decreases as the tropical cyclone 
strengthens due to the decrease in surface pressure- the integral is simply being performed over less mass. Therefore, when computing anomalies from the box average, the MSE anomaly $\hat{h^{\prime}}$ near the tropical cyclone is negative. As every term in the MSE variance budget [Eq. (A3)] includes $\hat{h}^{\prime}$ this severely complicates the interpretation of the budget. While still mathematically correct, it is no longer conceptually useful for relating covariability of sources and sinks of MSE and regions favorable for convection throughout the TC life cycle.

We considered two ways in which to rephrase the MSE and MSE variance budgets to account for the change in column mass. One option is to write a budget for column-integrated MSE per unit column mass. If the column mass is defined as

$$
m=\frac{1}{g} \int_{p_{t}}^{p_{b}} d p
$$

and the column integral per column mass of some variable $A$ is defined as

$$
\tilde{A}=\frac{1}{m g} \int_{p_{t}}^{p_{b}} A d p
$$

then the MSE budget can be written as

$$
\frac{\partial \tilde{h}}{\partial t}=\tilde{F}_{k}+\tilde{N}_{L}+\tilde{N}_{S}-\overline{\mathbf{u} \cdot \nabla h}+\frac{h_{p_{b}}-\tilde{h}}{m} \frac{\partial m}{\partial t}
$$

and an MSE variance budget can be formed as

$$
\begin{aligned}
\frac{1}{2} \frac{\partial}{\partial t} \tilde{h}^{\prime 2}=\tilde{h}^{\prime} \tilde{F}_{k}^{\prime}+\tilde{h}^{\prime} \tilde{N}_{L}^{\prime}+\tilde{h}^{\prime} \tilde{N}_{S}^{\prime}-\tilde{h^{\prime} \mathbf{u} \cdot \nabla h^{\prime}} \\
+\tilde{h}^{\prime}\left(\frac{h_{p_{b}}-\tilde{h}}{m} \frac{\partial m}{\partial t}\right)^{\prime} .
\end{aligned}
$$

These budgets are technically challenging to compute, as they involve extra terms involving the change in column mass. The interpretation of the feedback terms in the MSE variance budget would be more difficult as it would require thinking through covariability between column MSE, sources and sinks of MSE, and the column mass. An alternative option that is simpler both technically and conceptually, and allows easier comparison to previous work (Wing et al. 2016; Muller and Romps 2018), is to perform the column integral between two fixed pressure levels, such that the mass over which the integral is performed is the same at all times and grid boxes. A similar approach has been taken previously for MSE budget analysis of the MJO (Sobel et al. 2014). The MSE variability is then driven by changes in its diabatic and advective sources and sinks, which is easier to relate

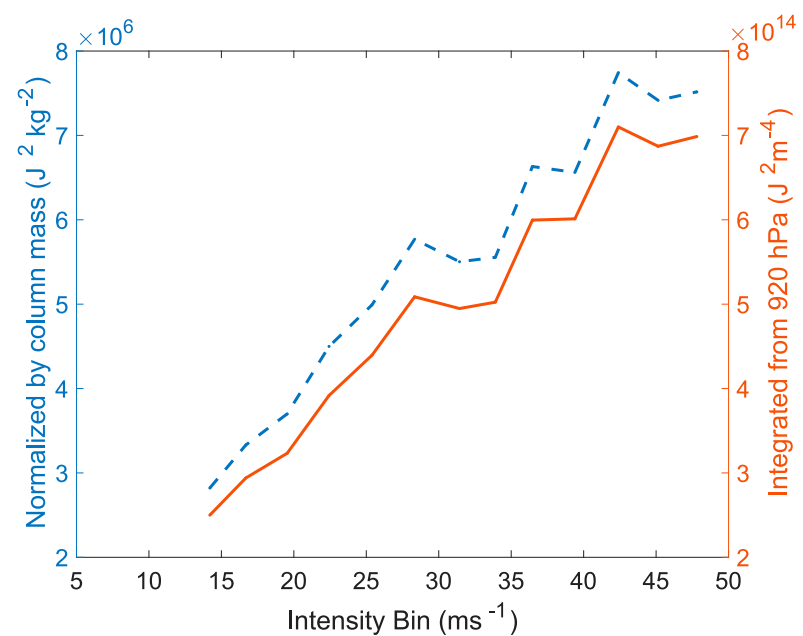

FIG. A1. Box average of MSE variance composited over intensity bins in the HiRAM simulation. The right axis (red line) shows the MSE variance based on column-integrated MSE integrated from $920 \mathrm{hPa}$. The left axis (blue dashed line) shows the MSE variance based on column-integrated MSE integrated over the whole column and normalized by the total column mass.

conceptually to favorability for convection. This is the approach taken in this paper; we set $p_{b}$ to $920 \mathrm{hPa}$. This value was chosen because it is lower than the vast majority of surface pressures in the simulated tropical cyclones we analyze, while still comfortably in the boundary layer. The minimum surface pressure is never below $920 \mathrm{hPa}$ in AM2.5, FLOR, and GEOS, and is below $920 \mathrm{hPa}$ in less than $0.5 \%$ of storm snapshots in HIRAM, less than $0.3 \%$ in CAM-FV, and less than $0.2 \%$ in CAM-SE.

As discussed in the main text, it is not obvious that there must be a strong connection between the spatial variance of MSE and TC intensity, but empirically the box-average MSE variance composited over intensity bins increases strongly with intensity, with a very close correspondence between the column MSE per column mass and column MSE integrated from $920 \mathrm{hPa}$ (Fig. A1). When the box-average MSE variance at the time of lifetime maximum intensity (LMI) is considered rather than the intensity-bin composite, this also has a statistical relationship with the value of LMI (Fig. A2). While there is scatter in the relationship, the two have a statistically significant correlation of $r=0.46$, or $r=0.39$ when column MSE per column mass is used (for the HiRAM simulation). The consistency between the behavior of column MSE per column mass and column MSE integrated from $920 \mathrm{hPa}$ gives us confidence in using the latter for our analysis methodology.

Specifically, we interpolate the moist static energy to a fixed pressure level of $p_{b}=920 \mathrm{hPa}$, and integrate from there to the next model level above, and then through 


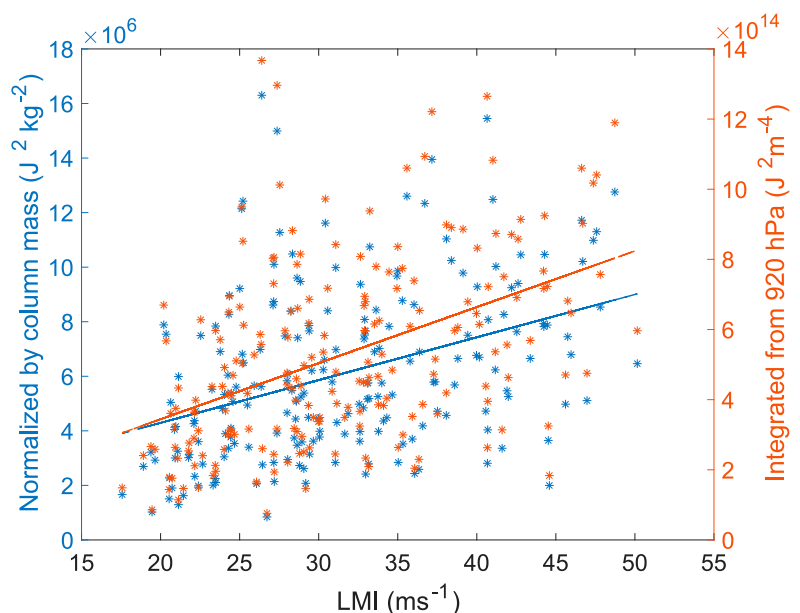

FIG. A2. Scatterplot of box-average MSE variance at the time of each storm's LMI against that storm's LMI, for the HiRAM simulation. The right axis (red points) shows the MSE variance based on column-integrated MSE integrated from $920 \mathrm{hPa}$. The left axis (blue points) shows the MSE variance based on column-integrated MSE integrated over the whole column and normalized by the total column mass. A linear regression line is shown for each.

the rest of the column on model levels. We note that this may introduce some error to the closure of the moist static energy budget, as the diabatic terms are evaluated at the surface rather than at $920 \mathrm{hPa}$. However, other errors introduced by interpolation onto a regular spatial grid and temporal sampling already are present and likely contribute more to budget imbalance. These imbalances imply that we must be cautious in our interpretation of the budget residual as representing the advective term, as it may contain some of these other factors. The rest of the calculation follows the description in section 3 and Eqs. (A1)-(A3).

\section{b. Neglect of kinetic energy}

Equation (2) is only an approximate conservation equation for MSE [Eq. (1)] because the generation of kinetic energy is neglected. Equations (1) and (2) are derived by considering the first law of thermodynamics phrased with pressure and temperature as the state variables: $c_{p} d T-\alpha d P=Q$ (Emanuel 1994). It is then assumed that $d P \approx d(g z)$, which ignores $\partial P / \partial t$, the advection of horizontal gradients of $P$, and the nonhydrostatic vertical pressure field, which eliminates the conversion to kinetic energy (Betts 1974). If there are large horizontal gradients of $P$, as there are in a tropical cyclone, this may be inaccurate.

To quantify the effect of this approximation, we compute the tendency of column-integrated kinetic energy and compare it to the tendency of column-integrated MSE, in the HiRAM simulation. After compositing relative to the time of lifetime maximum intensity, we (a) Box-average
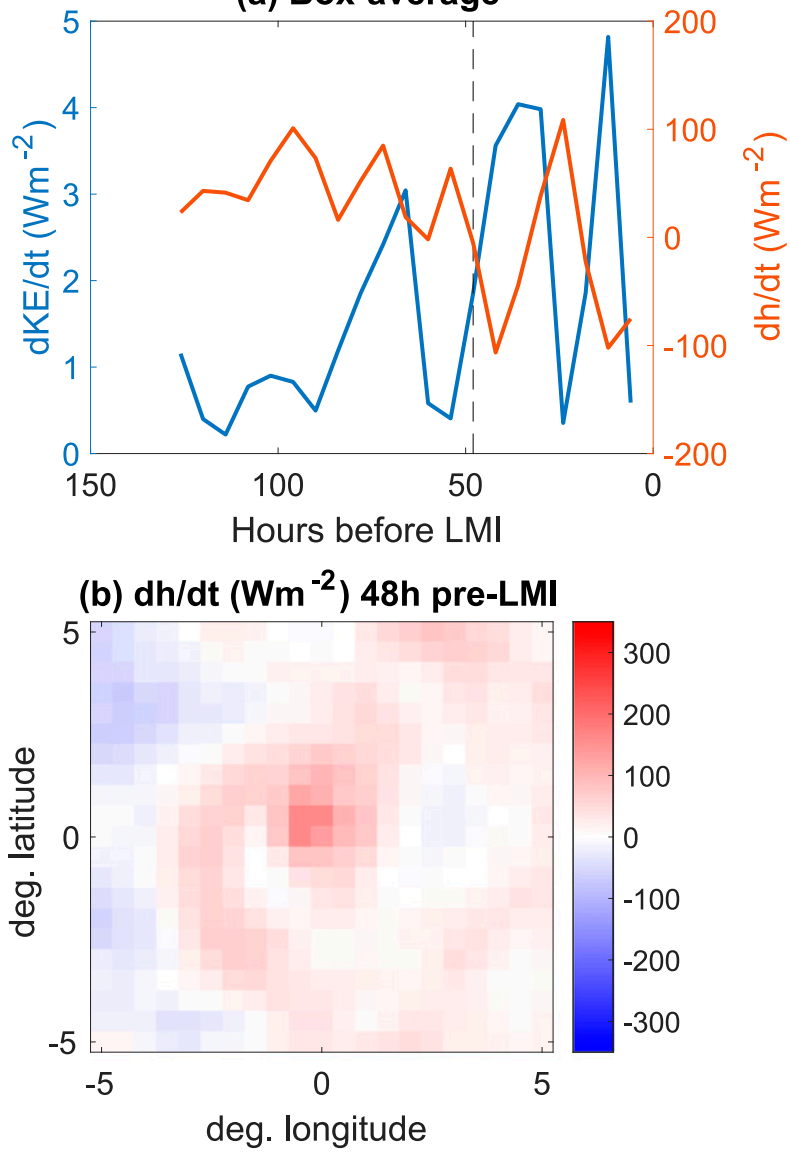

(c) dKE/dt $\left(\mathrm{Wm}^{-2}\right) 48 \mathrm{~h}$ pre-LMI

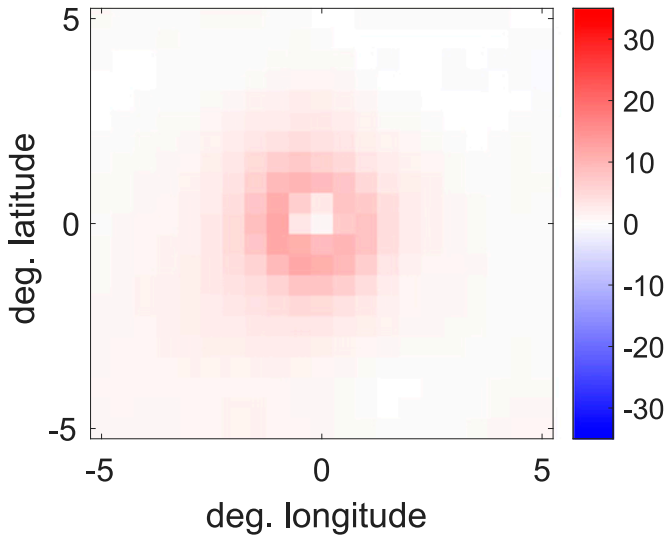

FIG. A3. (a) The tendency of column-integrated MSE (right axis; red line) and tendency of column-integrated kinetic energy (left axis; blue line). Each is box averaged and composited over all storms relative to the time of LMI. (b) The tendency of columnintegrated MSE as a function of latitude and longitude from the TC center, composited at $48 \mathrm{~h}$ prior to LMI. (c) The tendency of column-integrated kinetic energy as a function of latitude and longitude from the TC center, composited at $48 \mathrm{~h}$ prior to LMI. The HiRAM simulation is shown. 
find that the box-average kinetic energy tendency is two orders of magnitude smaller than the box-average MSE tendency (Fig. A3a). When we consider the composite $48 \mathrm{~h}$ prior to $\mathrm{LMI}$, the kinetic energy tendency is at least one order of magnitude smaller than the MSE tendency on a grid box by grid box basis (Figs. A3b,c). Note that here the column integral is performed between $920 \mathrm{hPa}$ and the model top, as it is in our MSE budget analysis. The small magnitude of the kinetic tendency relative to the MSE tendency gives us confidence that neglecting it does not seriously impact our results.

\section{REFERENCES}

Anderson J. L., and Coauthor, 2004: The new GFDL global atmosphere and land model AM2-LM2: Evaluation with prescribed SST simulations. J. Climate, 17, 4641-4673, https:// doi.org/10.1175/JCLI-3223.1.

Arnold, N. P., and D. A. Randall, 2015: Global-scale convective aggregation: Implications for the Madden-Julian oscillation. J. Adv. Model. Earth Syst., 7, 1499-1518, https://doi.org/ 10.1002/2015MS000498.

Becker, T., B. Stevens, and C. Hohenegger, 2017: Imprint of the convective parameterization and sea-surface temperature on large-scale convective self-aggregation. J. Adv. Model. Earth Syst., 9, 1488-1505, https://doi.org/10.1002/2016MS000865.

Betts, A., 1974: Further comments on "A comparison of the equivalent potential temperature and the static energy.' J. Atmos. Sci., 31, 1713-1715, https://doi.org/10.1175/15200469(1974)031<1713:FCOCOT>2.0.CO;2.

Bosilovich, M. G., and Coauthors, 2015: MERRA-2: Initial evaluation of the climate. NASA/TM-2015-14606, Vol. 43, $139 \mathrm{pp.}$ https://gmao.gsfc.nasa.gov/pubs/docs/Bosilovich803.pdf.

Bretherton, C. S., and S. Park, 2009: A new moist turbulence parameterization in the Community Atmosphere Model. J. Climate, 22, 3422-3448, https://doi.org/10.1175/2008JCLI2556.1.

— J. J. R. McCaa, and H. Grier, 2004: A new parameterization for shallow cumulus convection and its application to marine subtropical cloud-topped boundary layers. Part I: Description and 1D results. Mon. Wea. Rev., 132, 864-882, https://doi.org/ 10.1175/1520-0493(2004)132<0864:ANPFSC > 2.0.CO;2.

$\mathrm{Bu}$, Y., R. Fovell, and K. Corbosiero, 2014: Influence of cloudradiative forcing on tropical cyclone structure. J. Atmos. Sci., 71, 1644-1662, https://doi.org/10.1175/JAS-D-13-0265.1.

$\ldots, \ldots$, and 2017: The influences of boundary layer mixing and cloud-radiative forcing on tropical cyclone size. J. Atmos. Sci., 74, 1273-1292, https://doi.org/10.1175/JAS-D16-0231.1.

Camargo, S. J., 2013: Global and regional aspects of tropical cyclone activity in the CMIP5 models. J. Climate, 26, 9880-9902, https://doi.org/10.1175/JCLI-D-12-00549.1.

- and S. E. Zebiak, 2002: Improving the detection and tracking of tropical cyclones in atmospheric general circulation models. Wea. Forecasting, 17, 1152-1162, https://doi.org/10.1175/15200434(2002)017<1152:ITDATO>2.0.CO;2.

-, and A. Wing, 2016: Tropical cyclones in climate models. Wiley Interdiscip. Rev.: Climate Change, 7, 211-237, https:// doi.org/10.1002/wcc.373.
Chen, J.-H., and S.-J. Lin, 2011: The remarkable predictability of inter-annual variability of Atlantic hurricanes during the past decade. Geophys. Res. Lett., 38, L11804, https://doi.org/ 10.1029/2011GL047629.

, and -2013 : Seasonal predictions of tropical cyclones using a $25-\mathrm{km}$-resolution general circulation model. J. Climate, 26, 380-398, https://doi.org/10.1175/JCLI-D-12-00061.1.

Chou, M.-D., and M. J. Suarez, 1994: An efficient thermal infrared radiation parameterization for use in general circulation models. NASA Tech. Memo. 104606, Vol. 3, 93 pp. , and - 1999: A solar radiation parameterization for atmospheric studies. NASA Tech. Memo. 104606, Vol. 15, 51 pp.

Chu, J.-H., C. Sampson, A. Levine, and E. Fukada, 2002: The Joint Typhoon Warming Center tropical cyclone best-tracks, 1945-2000. NRL Tech. Rep. NRL/MR/7540-02-16, https://www. metoc.navy.mil/jtwc/products/best-tracks/tc-bt-report.html.

Collow, A., S. P. Mahanama, M. G. Bosilovich, R. D. Koster, and S. D. Schubert, 2017: An evaluation of teleconnections over the United States in an ensemble of AMIP simulations with the MERRA-2 configuration of the GEOS atmospheric model. NASA/TM-2017-104606, Vol. 47, 78 pp., https:// gmao.gsfc.nasa.gov/pubs/docs/Collow963.pdf.

, M. G. Bosilovich, and R. Lucchesi, 2018: File specification for M2AMIP products. GMAO Office Note 15 (version 1.0), 45 pp., https://gmao.gsfc.nasa.gov/pubs/docs/Collow1024.pdf.

Coppin, D., and S. Bony, 2015: Physical mechanisms controlling the initiation of convective self-aggregation in a general circulation model. J. Adv. Model. Earth Syst., 7, 2060-2078, https://doi.org/10.1002/2015MS000571.

Delworth, T. L., and Coauthors, 2012: Simulated climate and climate change in the GFDL CM2.5 high-resolution coupled climate model. J. Climate, 25, 2755-2781, https://doi.org/ 10.1175/JCLI-D-11-00316.1.

Dennis, J., and Coauthors, 2012: CAM-SE: A scalable spectral element dynamical core for the Community Atmosphere Model. Int. J. High Perform. Comput. Appl., 26, 74-89, https:// doi.org/10.1177/1094342011428142.

Duvel, J., S. Camargo, and A. Sobel, 2017: Role of convection scheme in modeling initiation and intensification of tropical depressions over the North Atlantic. Mon. Wea. Rev., 145, 1495-1509, https://doi.org/10.1175/MWR-D-16-0201.1.

Emanuel, K., 1994: Atmospheric Convection. Oxford University Press, $580 \mathrm{pp}$

Fovell, R., K. L. Corbosiero, A. Seifert, and K.-N. Liou, 2010: Impact of cloud-radiative processes on hurricane track. Geophys. Res. Lett., 37, L07808, https://doi.org/10.1029/2010GL042691.

—, Y. P. Bu, K. L. Corbosiero, W. Tung, Y. Cao, H.-C. Kuo, L. Hsu, and H. Su, 2016: Influence of cloud microphysics and radiation on tropical cyclone structure and motion. Multiscale ConvectionCoupled Systems in the Tropics: A Tribute to Dr. Michio Yanai, Meteor. Monogr., Amer. Meteor. Soc., No. 56, 11.1-11.27, https://doi.org/10.1175/AMSMONOGRAPHS-D-15-0006.1.

Gelaro, R., and Coauthors, 2017: The Modern-Era Retrospective Analysis for Research and Applications, version 2 (MERRA-2). J. Climate, 30, 5419-5454, https://doi.org/10.1175/JCLI-D16-0758.1.

Halperin, D. J., H. E. Fuelberg, R. E. Hart, and J. H. Cossuth, 2016: Verification of tropical cyclone genesis forecasts from global numerical models: Comparisons between the North Atlantic and eastern North Pacific basins. Wea. Forecasting, 31, 947955, https://doi.org/10.1175/WAF-D-15-0157.1.

Harris, L. M., S.-J. Lin, and C.-Y. Tu, 2016: High-resolution climate simulations using GFDL HiRAM with a stretched global grid. 
J. Climate, 29, 4293-4314, https://doi.org/10.1175/JCLI-D-150389.1.

Hohenegger, C., and B. Stevens, 2016: Coupled radiative convective equilibrium simulations with explicit and parameterized convection. J. Adv. Model. Earth Syst., 8, 1468-1482, https:// doi.org/10.1002/2016MS000666.

Holloway, C. E., 2017: Convective aggregation in realistic convective-scale simulations. J. Adv. Model. Earth Syst., 9, 1450-1472, https://doi.org/10.1002/2017MS000980.

—, and S. J. Woolnough, 2016: The sensitivity of convective aggregation to diabatic processes in idealized radiativeconvective equilibrium simulations. J. Adv. Model. Earth Syst., 8, 166-195, https://doi.org/10.1002/2015MS000511.

Hurrell, J. W., J. J. Hack, D. Shea, J. M. Caron, and J. Rosinski, 2008: A new sea surface temperature and sea ice boundary dataset for the Community Atmosphere Model. J. Climate, 21, 5145-5153, https://doi.org/10.1175/2008JCLI2292.1.

Kim, D., A. H. Sobel, A. D. Del Genio, Y. Chen, S. J. Camargo, M.-S. Yao, M. Kelley, and L. Nazarenko, 2012: The tropical subseasonal variability simulated in the NASA GISS general circulation model. J. Climate, 25, 4641-4659, https://doi.org/ 10.1175/JCLI-D-11-00447.1.

— , and Coauthors, 2018: Process-oriented diagnosis of tropical cyclones in high-resolution GCMs. J. Climate, 31, 1685-1702, https://doi.org/10.1175/JCLI-D-17-0269.1.

Knutson, T. R., J. J. Sirutis, S. T. Garner, I. M. Held, and R. E. Tuleya, 2007: Simulation of the recent multidecadal increase of Atlantic hurricane activity using an 18-km-grid regional model. Bull. Amer. Meteor. Soc., 88, 1549-1565, https:// doi.org/10.1175/BAMS-88-10-1549.

Landsea, C., and J. Franklin, 2013: Atlantic hurricane database uncertainty and presentation of new database format. Mon. Wea. Rev., 141, 3576-3592, https://doi.org/10.1175/MWR-D-12-00254.1.

Lee, C.-Y., M. Tippett, A. Sobel, and S. Camargo, 2016: Rapid intensification and the bimodal distribution of tropical cyclone intensity. Nat. Commun., 7, 10625, https://doi.org/10.1038/ NCOMMS10625.

Lim, Y.-K., S. D. Schubert, O. Reale, M.-I. Lee, A. M. Molod, and M. J. Suarez, 2015: Sensitivity of tropical cyclones to parameterized convection in the NASA GEOS-5 model. J. Climate, 28, 551-573, https://doi.org/10.1175/JCLI-D-14-00104.1.

Lin, S.-J., and R. B. Rood, 1996: Multidimensional flux-form semi-Lagrangian transport schemes. Mon. Wea. Rev., 124, 2046-2070, https://doi.org/10.1175/1520-0493(1996)124<2046: MFFSLT $>2.0 . \mathrm{CO} ; 2$.

—, and —, 1997: An explicit flux-form semi-Lagrangian shallow-water model on the sphere. Quart. J. Roy. Meteor. Soc., 123, 2477-2498, https://doi.org/10.1002/qj.49712354416.

Lloyd, I. D., and G. A. Vecchi, 2011: Observational evidence for oceanic controls on hurricane intensity. J. Climate, 24, 11381153, https://doi.org/10.1175/2010JCLI3763.1.

Manganello, J., and Coauthors, 2012: Tropical cyclone climatology in a 10-km global atmospheric GCM: Toward weather-resolving climate modeling. J. Climate, 25, 3867-3893, https://doi.org/ 10.1175/JCLI-D-11-00346.1.

Melhauser, C., and F. Zhang, 2014: Diurnal radiation cycle impact on the pregenesis environment of Hurricane Karl (2010). J. Atmos. Sci., 71, 1241-1259, https://doi.org/10.1175/JAS-D-13-0116.1.

Mlawer, E. J., S. J. Taubman, P. D. Brown, M. J. Iacono, and S. A. Clough, 1997: Radiative transfer for inhomogeneous atmospheres: RRTM, a validated correlated- $k$ model for the longwave. J. Geophys. Res., 102, 16 663-16 682, https://doi.org/ 10.1029/97JD00237.
Molod, A., L. Takacs, M. Suarez, and J. Bacmeister, 2015: Development of the GEOS-5 atmospheric general circulation model: Evolution from MERRA to MERRA2. Geosci. Model Dev., 8, 1339-1356, https://doi.org/10.5194/gmd-81339-2015.

Moorthi, S., and M. J. Suarez, 1992: Relaxed Arakawa-Schubert: A parameterization of moist convection for general circulation models. Mon. Wea. Rev., 120, 978-1002, https://doi.org/10.1175/ 1520-0493(1992)120<0978:RASAPO > 2.0.CO;2.

Muller, C. J., and D. M. Romps, 2018: Acceleration of tropical cyclogenesis by self-aggregation feedbacks. Proc. Natl. Acad. Sci. USA, 115, 2930-2935, https://doi.org/10.1073/PNAS. 1719967115.

Murakami, H., and Coauthors, 2012: Future changes in tropical cyclone activity projected by the new high-resolution MRIAGCM. J. Climate, 25, 3237-3260, https://doi.org/10.1175/ JCLI-D-11-00415.1.

— and 5 hurricanes in the high-resolution GFDL HiFLOR coupled climate models. J. Climate, 28, 9058-9079, https://doi.org/ 10.1175/JCLI-D-15-0216.1.

_ , G. Villarini, G. A. Vecchi, W. Zhang, and R. Gudgel, 2016: Statistical-dynamical seasonal forecast of North Atlantic and U.S. landfalling tropical cyclones using the high-resolution GFDL FLOR coupled models. Mon. Wea. Rev., 144, 21012123, https://doi.org/10.1175/MWR-D-15-0308.1.

Navarro, E. L., and G. J. Hakim, 2016: Idealized numerical modeling of the diurnal cycle of tropical cyclones. J. Atmos. Sci., 73, 4189-4201, https://doi.org/10.1175/JAS-D-15-0349.1.

Neale, R., and Coauthors, 2012: Description of the NCAR Community Atmosphere Model (CAM 5.0). NCAR Tech. Note TN-486, 274 pp., http://www.cesm.ucar.edu/models/cesm1.0/ cam/docs/description/cam5_desc.pdf.

Nicholls, M. E., 2015: An investigation of how radiation may cause accelerated rates of tropical cyclogenesis and diurnal cycles of convective activity. Atmos. Chem. Phys., 15, 9003-9029, https://doi.org/10.5194/acp-15-9003-2015.

O’Neill, M., D. Perez-Betancourt, and A. A. Wing, 2017: Accessible environments for diurnal-period waves in simulated tropical cyclones. J. Atmos. Sci., 74, 2489-2502, https://doi.org/ 10.1175/JAS-D-16-0294.1.

Park, S., and C. S. Bretherton, 2009: The University of Washington shallow convection and moist turbulence schemes and their impact on climate simulations with the Community Atmosphere Model. J. Climate, 22, 3449-3469, https://doi.org/ 10.1175/2008JCLI2557.1.

Putman, W., and S.-J. Lin, 2007: Finite-volume transport on various cubed-sphere grids. J. Comput. Phys., 227, 55-78, https:// doi.org/10.1016/J.JCP.2007.07.022.

Rayner, N. A., D. E. Parker, E. B. Horton, C. K. Folland, L. V. Alexander, and D. P. Rowell, 2003: Global analysis of sea surface temperature, sea ice, and night marine air temperature since the late nineteenth century. J. Geophys. Res., 108, 4407, https://doi.org/10.1029/2002JD002670.

Reed, K. A., and C. Jablonowski, 2011: Impact of physical parameterizations on idealized tropical cyclones in the Community Atmosphere Model. Geophys. Res. Lett., 38, L04805, https://doi.org/10.1029/2010GL046297.

_ J. T. Bacmeister, N. A. Rosenbloom, M. F. Wehner, S. C. Bates, P. H. Lauritzen, J. E. Truesdale, and C. Hannay, 2015: Impact of the dynamical core on the direct simulation of tropical cyclones in a high-resolution global model. Geophys. Res. Lett., 42, 3603-3608, https://doi.org/10.1002/2015GL063974. 
Rienecker, M., and Coauthors, 2008: The GEOS-5 data assimilation system-Documentation of versions 5.0.1, 5.1.0, and 5.2.0. NASA/TM-2008-104606, Vol. 27, 101 pp., https:/gmao.gsfc. nasa.gov/pubs/docs/Rienecker369.pdf.

Roberts, M., and Coauthors, 2015: Tropical cyclones in the UPSCALE ensemble of high-resolution global climate models. J. Climate, 28, 574-596, https://doi.org/10.1175/JCLI-D-14-00131.1.

Scoccimarro, E., S. Gualdi, G. Villarini, G. Vecchi, M. Zhao, K. Walsh, and A. Navarra, 2014: Intense precipitation events associated with landfalling tropical cyclones in response to a warmer climate and increased $\mathrm{CO}_{2}$. J. Climate, 27, 4642-4654, https://doi.org/10.1175/JCLI-D-14-00065.1.

—, P. Fogli, K. Reed, S. Gualdi, S. Masina, and A. Navarra, 2017: Tropical cyclone interaction with the ocean: The role of highfrequency (subdaily) coupled processes. J. Climate, 30, 145162, https://doi.org/10.1175/JCLI-D-16-0292.1.

Shaevitz, D. A., and Coauthors, 2014: Characteristics of tropical cyclones in high-resolution models in the present climate. J. Adv. Model. Earth Syst., 6, 1154-1172, https://doi.org/ 10.1002/2014MS000372.

Sobel, A., S. Wang, and D. Kim, 2014: Moist static energy budget of the MJO during DYNAMO. J. Atmos. Sci., 71, 4276-4429, https://doi.org/10.1175/JAS-D-14-0052.1.

Tang, X., and F. Zhang, 2016: Impacts of the diurnal radiation cycle on the formation, intensity, and structure of Hurricane Edouard (2014). J. Atmos. Sci., 73, 2871-2892, https://doi.org/ 10.1175/JAS-D-15-0283.1.

Ullrich, P. A., and C. M. Zarzycki, 2017: TempestExtremes: A framework for scale-insensitive pointwise feature tracking on unstructured grids. Geosci. Model Dev., 10, 1069-1090, https:// doi.org/10.5194/gmd-10-1069-2017.

Vecchi, G. A., and Coauthors, 2014: On the seasonal forecasting of regional tropical cyclone activity. J. Climate, 27, 7994-8016, https://doi.org/10.1175/JCLI-D-14-00158.1.

Villarini, G., D. Lavers, E. Scoccimarro, M. Zhao, M. Wehner, G. Vecchi, T. Knutson, and K. Reed, 2014: Sensitivity of tropical cyclone rainfall to idealized global-scale forcings. J. Climate, 27, 4622-4641, https://doi.org/10.1175/JCLI-D-1300780.1

Vitart, F., J. L. Anderson, and W. F. Stern, 1997: Simulation of interannual variability of tropical storm frequency in an ensemble of GCM integrations. J. Climate, 10, 745-760, https://doi.org/ 10.1175/1520-0442(1997)010<0745:SOIVOT $>2.0 . C O ; 2$.

- D. Anderson, and T. Stockdale, 2003: Seasonal forecasting of tropical cyclone landfall over Mozambique. J. Climate, 16, 3932-3945, https://doi.org/10.1175/1520-0442(2003)016<3932: SFOTCL $>2.0 . \mathrm{CO} ; 2$.

, A. Leroy, and M. C. Wheeler, 2010: A comparison of dynamical and statistical predictions of weekly tropical cyclone activity in the Southern Hemisphere. Mon. Wea. Rev., 138, 3671-3682, https://doi.org/10.1175/2010MWR3343.1.
Walsh, K., and Coauthors, 2016: Tropical cyclones and climate change. Wiley Interdiscip. Rev.: Climate Change, 7, 65-89, https://doi.org/10.1002/wcc.371.

Wehner, M. F., and Coauthors, 2014: The effect of horizontal resolution on simulation quality in the Community Atmospheric Model, CAM5.1. J. Adv. Model. Earth Syst., 6, 980997, https://doi.org/10.1002/2013MS000276.

Wing, A. A., and K. A. Emanuel, 2014: Physical mechanisms controlling self-aggregation of convection in idealized numerical modeling simulations. J. Adv. Model. Earth Syst., 6, 59-74, https://doi.org/10.1002/2013MS000269.

— , and T. W. Cronin, 2016: Self-aggregation of convection in long channel geometry. Quart. J. Roy. Meteor. Soc., 142, 1-15, https://doi.org/10.1002/qj.2628.

_ S. J. Camargo, and A. H. Sobel, 2016: Role of radiativeconvective feedbacks in spontaneous tropical cyclogenesis in idealized numerical simulations. J. Atmos. Sci., 73, 2633-2642, https://doi.org/10.1175/JAS-D-15-0380.1.

Zarzycki, C. M., 2016: Tropical cyclone intensity errors associated with lack of two-way ocean coupling in high-resolution global simulations. J. Climate, 29, 8589-8610, https://doi.org/10.1175/ JCLI-D-16-0273.1.

- M. N. Levy, C. Jablonowski, J. R. Overfelt, M. A. Taylor, and P. A. Ullrich, 2014: Aquaplanet experiments using CAM's variable-resolution dynamical core. J. Climate, 27, 5481-5503, https://doi.org/10.1175/JCLI-D-14-00004.1.

, K. A. Reed, J. T. Bacmeister, A. P. Craig, S. C. Bates, and N. A. Rosenbloom, 2016: Impact of surface coupling grids on tropical cyclone extremes in high-resolution atmospheric simulations. Geosci. Model Dev., 9, 779-788, https://doi.org/ 10.5194/GMD-9-779-2016.

— D. R. Thatcher, and C. Jablonowski, 2017: Objective tropical cyclone extratropical transition detection in high-resolution reanalysis and climate model data. J. Adv. Model. Earth Syst., 9, 130-148, https://doi.org/10.1002/2016MS000775.

Zhang, G., and N. A. McFarlane, 1995: Sensitivity of climate simulations to the parameterization of cumulus convection in the $\mathrm{Ca}$ nadian Climate Centre general circulation model. Atmos.-Ocean, 33, 407-446, https://doi.org/10.1080/07055900.1995.9649539.

Zhang, W., and Coauthors, 2016: Improved simulation of tropical cyclone responses to ENSO in the western North Pacific in the high-resolution GFDL HiFLOR coupled climate model. J. Climate, 29, 1391-1415, https://doi.org/10.1175/JCLI-D-150475.1.

Zhao, M., I. M. Held, S.-J. Lin, and G. A. Vecchi, 2009: Simulations of global hurricane climatology, interannual variability, and response to global warming using a $50-\mathrm{km}$ resolution GCM. J. Climate, 22, 6653-6678, https://doi.org/10.1175/2009JCLI3049.1. and - 2012: Some counterintuitive dependencies of tropical cyclone frequency on parameters in a GCM. J. Atmos. Sci., 69, 2272-2283, https://doi.org/10.1175/JAS-D-11-0238.1. 